\title{
Protección y reconocimiento institucional y jurisprudencial del derecho humano a la salud en el establecimiento penitenciario de Tunja
}

Institucional and jurisprudential protection and recognition of the human right to the health in the penitential and prison establishment of Tunja

Autor: Nicolás David Rodríguez Forero

DOl: https://doi.org/10.19053/16923936.v19.n37.2021.13014

Para citar este artículo:

Rodríguez Forero, N. D. (2021). Protección y reconocimiento institucional y jurisprudencial del derecho humano a la salud en el establecimiento penitenciario de Tunja. Derecho y Realidad, 19 (37), 161-194. 


\section{PROTECCIÓN Y RECONOCIMIENTO INSTITUCIONAL Y JURISPRUDENCIAL DEL DERECHO HUMANO A LA SALUD EN EL ESTABLECIMIENTO PENITENCIARIO DE TUNJA*}

Institucional and jurisprudential protection and recognition of the human right to the health in the penitential and prison establishment of Tunja

\section{Nicolás David Rodríguez Forero}

Abogado Universidad Santo Tomás Seccional Tunja. Conciliador en Derecho y Magister en Derechos

Humanos de la Universidad Pedagógica y Tecnológica de Colombia -UPTC-.

nicolasdavid1990@gmail.com

Recepción: Octubre 9 de 2020

Aceptación: Mayo 5 de 2021

\section{RESUMEN}

El campo de la protección, reconocimiento y responsabilidad del derecho humano a la salud en personas privadas de la libertad en el contexto tunjano, permite explorar y explicar la intervención institucional sobre el alcance prestacional fundamental de este derecho, tomando las visiones de orden institucional, administrativo, judicial y de organismos de control humanitario, como son el EPMSC ${ }^{1}$ de Tunja, Personería Municipal, Defensoría del Pueblo y Secretaría de Salud de Boyacá dentro del marco del Estado de Cosas Inconstitucional y de la protección a este colectivo poblacional

* Artículo de investigación derivado de la tesis de Maestría en Derechos Humanos titulada: "Protección y Reconocimiento del Derecho Humano a la Salud en personas privadas de la libertad en el Establecimiento Penitenciario y Carcelario de Tunja".

1. Establecimiento Penitenciario de Mediana Seguridad y Carcelario de Tunja. en el contexto del articulado legal y constitucional en el periodo 2002-2019.

\section{PALABRAS CLAVES}

Salud; presos; Estado de Cosas Inconstitucional; responsabilidad; derecho; protección; determinantes sociales.

\section{ABSTRACT}

The field of protection, recognition and responsibility of the human right to health for persons deprived of liberty in the context of Tunja, allows us to explore and explain the institutional intervention on the fundamental scope of this right, taking the institutional, administrative, judicial and humanitarian control bodies' visions, such as the EPMSC of Tunja, the Municipal Ombudsman, the Ombudsman's Office and the Health 
Secretariat of Boyacá within the framework of the unconstitutional state of affairs and the protection of this population group in the context of the legal and constitutional articulation in the period 2002-2019.

\section{KEYWORDS}

Health; prisoners; Unconstitutional State of Things; responsibility; right; protection; social determined.

\section{INTRODUCCIÓN}

El fundamento de los derechos humanos (en adelante DDHH) implica el uso adecuado, la protección y reconocimiento a sujetos poblacionales colectivos que se encuentran en situación de indefensión e inferioridad, comprendiendo que Colombia es un Estado Social de Derecho, que respeta la dignidad humana, que se encuentra adherida a los tratados internacionales relativos a DDHH, y al otorgamiento de la primacía del interés general, en donde el rol del ser humano frente al Estado, abre mejores espacios de transformación y cambio hacia sus condiciones de existencia.

Partiendo de lo anterior, se debe mencionar el hecho de que la inclusión de los DDHH en personas privadas de la libertad (en adelante PPL), es vital para la concreción de elementos que avoquen en la defensa, la legitimidad y la exigibilidad de sus derechos, en especial la salud, ya que a pesar de ser vistos como derechos económicos, sociales y culturales (DESC), configuran un desarrollo constante y permanente en virtud de la Constitución de 1991, el cual permite inferir que la declaratoria del Estado de Cosas Inconstitucional, la emergencia sanitaria y carcelaria, y el déficit de la infraestructura física en los establecimientos penitenciarios en el contexto colombiano han abierto el diálogo. Esto último a fin de concientizar la solidaridad social de este sector poblacional mediante la participación de veedores ciudadanos, organismos de control humanitario, y el Gobierno, para garantizar condiciones dignas y valoración prioritaria de las PPL.
En segundo lugar, bajo el contexto social e institucional actual que se presenta por la declaratoria de emergencia carcelaria, es necesario recalcar que el estudio no solo trae consigo una valoración de registro documental sobre dicha problemática humanitaria, sino que además a nivel municipal, mediante el recogimiento de experiencias por parte de funcionarios revestidos de autoridad carcelaria (INPEC), organismos estatales (Secretaría de Salud de Boyacá), de control humanitario (Personería y Defensoría del Pueblo), y de prestadores de salud (EPMSC de Tunja, Sanidad), se debe diagnosticar, en última instancia, la caracterización de este sector poblacional mediante el uso de entrevistas que abarque principalmente la satisfacción, la exigibilidad, la prestación, la promoción, la prevención y la atención en acceso a la salud, en el establecimiento penitenciario de mediana seguridad y carcelario del municipio de Tunja en el periodo 2002-2019.

Por último, se valida el resultado de la presente investigación, teniendo en cuenta el diseño metodológico, a través del análisis cualitativo-documental y los resultados obtenidos, por medio de los cuales se dejan como producto los hallazgos y conclusiones sustantivas respecto del particular, con el objetivo de evaluar criterios relacionados con determinantes sociales, administración en la prestación del servicio médico y asistencial, y los alcances adoptados para agrupar la construcción y el diseño de estrategias, que posibiliten el acompañamiento, la exigibilidad y la defensa de las PPL. Estos temas se rescatan principalmente en el predominio, la consecución y la lucha constante de los DDHH en PPL.

\section{METODOLOGÍA}

La presente es una investigación cualitativa, interpretativa y documental que con base en el establecimiento jurisprudencial, el marco normativo legal y reglamentario en materia de accesibilidad en la prestación de los servicios de salud para la PPL, busca la materialización de efectividad y amparo de este derecho fundamental en el Establecimiento Penitenciario de Mediana 
Seguridad y Carcelario de Tunja (en adelante EPMSC de Tunja), bajo el principio de la relación especial de sujeción, propendiendo por el respeto de la dignidad humana, como facultad intrínseca y extrínseca que tiene el ser humano, en especial, la funcionalidad al goce efectivo y crítico de los DDHH y de la aplicabilidad del principio pro homine.

\section{OBJETIVO}

Explicar los alcances prestacionales de la protección, reconocimiento y responsabilidad administrativa del derecho humano a la salud en personas privadas de la libertad en el Establecimiento Penitenciario de Mediana Seguridad y Carcelario de Tunja.

\section{RESULTADOS: ESCENARIO LOCAL-ESTABLECIMIENTO PENITENCIARIO DE MEDIANA SEGURIDAD Y CARCELARIO DE TUNJA}

En primer lugar, en el establecimiento penitenciario de mediana seguridad y carcelario de Tunja, como en los demás ERON $^{2}$, presenta hacinamiento de PPL que inclusive, en un informe de seguimiento llevado a cabo por la Defensoría del PuebloRegional Boyacá, (2005), halló como población dentro del centro penitenciario, 111 personas PPL, de los cuales 100 son sindicados y 11 condenados; evidenciando principalmente que en materia de goce efectivo de DDHH, como la prestación y acceso al servicio de salud y la alimentación, se presta de forma irregular e insalubre, por ende, en esa oportunidad se dieron por sentadas las siguientes observaciones en conjunto con el integrante del comité de $\mathrm{DDHH}^{3}$ :

El EPMSC de Tunja es tranquila, en donde hay acceso a dialogar con el director, respecto de los problemas y dificultades que se pueden presentar en los patios;

2. Establecimientos Reclusorios del Orden Nacional.

3. Hernando Ortega, Sindicado por Rebelión, 18 meses - Integrante del Comité de Derechos Humanos (EPMSC), Tunja. en cuanto a salud y alimentación, afirma que se presentan dificultades mediatas para el traslado de enfermos a los centros asistenciales, así mismo, en la atención del servicio médico programado, por cuanto los contratos con las IPS no se renuevan con la debida oportunidad, manifiesta igualmente que a los internos no se le suministra útiles de aseo personal; ni siquiera al momento de ingreso (Defensoría del PuebloRegional Boyacá, 2005, p. 10).

Se tiene como observaciones frente al establecimiento, las siguientes:

i) Se encontraron alimentos, en mal estado y con fecha de consumo vencida; ii) presencia de moscas en cocina, depósito de alimentos, patios y alojamientos; iii) se presentan dificultades en la remisión de los internos para la valoración médica por parte de las IPS, y en la autorización por parte del INPEC, a través del convenio del Complejo Penitenciario y Carcelario de Cómbita; iv) se observó en el consultorio médico, recipiente de materiales inservibles y contaminados cerca de medicamentos y material paramédico (gasas, agua, vendas, agujas, alcohol antiséptico, isodine); v) ausencia de equipos de servicios de urgencias (bala de oxígeno-equipo de reanimación); vi) el valor nutricional de los alimentos observados y suministrados es deficiente; vii) los internos consumen los alimentos en las celdas. (Defensoría del Pueblo-Regional Boyacá, 2005, pp. 10-11)

Evidentemente, el EPMSC de Tunja, en un primer escenario de intervención por parte de los entes de control humanitario, deja ver que los alcances prestacionales de protección de los DDHH, como la salud, han sido parte también de las problemáticas estructurales que se tienen en materia de política criminal, que incluso la situación de hacinamiento, violación masiva de los DDHH, reclusión conjunta de personas sindicadas y condenadas, falta de articulación de las entidades territoriales 
y el Ministerio de Justicia son causas que deben ser replanteadas para mejorar y enfocar mediante esfuerzos institucionales, administrativos y presupuestales, en las que se ampare por una mejor condición de bienestar y de vida de la PPL (Sentencia T-762 de 2015).

Este tipo de observación refleja principalmente un estado tenue y débil en la prestación de los servicios médicos y asistenciales en el escenario penitenciario tunjano, que incluso a pesar de ser pacífica la convivencia entre las PPL y el Estado (autoridades carcelarias), los derechos a la vida, salud y acceso a la alimentación son objeto de desprotección y falta de ejecución de un mejor servicio al interior del penal.

Por otra parte, mediante Informe de Rendición de Cuentas de 2012, los directores regional central y distrital de Tunja, Ostos y Pardo (2012), manifestaron lo siguiente:

El EPMSC de Tunja a través del ejercicio de la atención social, especialmente en lo relacionado con la prestación del servicio a la salud, se cuenta con un (1) médico de medio tiempo nombrado por el INPEC, que cumple funciones administrativas, y el personal médico nombrado por CAPRECOM, encargado de la atención básica del personal de los internos.

Como también, se busca: i) citas con especialistas; ii) coordinación de prestación de servicios de salud a internos de sistema contributivo; iii) reclamación de reportes de red externa, iv) realización de exámenes de ingreso y egreso; v) valoraciones y conceptos para traslado; vi) trabajo mancomunado con el personal de salud de CAPRECOM para brindar atención integral a los internos del establecimiento (pp. 20-21).

De acuerdo con ello, es preciso rescatar que la PPL, a cargo del EPMSC de Tunja, no es ajena a prestar y acceder al derecho fundamental a la salud, sino que también al ser un servicio público esencial debe velar en condiciones dignas a garantizar este derecho humano, especialmente cuando se sitúa en una verdadera relación especial de sujeción, que en últimas logre el tratamiento penitenciario y de rehabilitación, para integrar el sujeto privado de la libertad a la comunidad, como ser creativo, productivo y autogestionario al recobrar su libertad.

En segundo lugar, en lo que respecta al hacinamiento carcelario, se identifica localmente que en el EPMSC de Tunja se presentó, para 2016, sobrepoblación aproximada de 232, excediendo la capacidad del centro reclusorio aproximadamente el $85 \%{ }^{4}$, dirigida exclusivamente a la población sindicada, así como posteriormente se aumentó a junio de 2016 la cifra a 94.1\%, situación que generó condiciones de insalubridad, al punto que el costo por persona es de $\$ 1.500 .000$ pesos, y el equivalente de 80 sindicados dentro del establecimiento, correspondiente a 180 millones de pesos mensuales (Diario Extra, 2016), afectando el goce efectivo de los DDHH.

A fin de evitar la problemática de hacinamiento penitenciario, el EPMSC de Tunja adoptó como medidas de choque las siguientes:

i) Solicitud ante el Juez coordinador de los Juzgados de Ejecución de Penas y Medidas de seguridad y Juzgados de Control de Garantías, de no remitir ni enviar internos a este establecimiento, teniéndose en cuenta

\footnotetext{
4. La Administración Municipal de Tunja citó a Consejo extraordinario de seguridad por problemática de hacinamiento en el centro penitenciario de Tunja. Durante reunión llevada a cabo en el despacho municipal, con la participación del alcalde de Tunja, Pablo Emilio Cepeda; el secretario de Gobierno, Fabio Martínez; la directora de la Fiscalía General de la Nación seccional Boyacá, Gladys Medina; y el director del Centro Penitenciario de Tunja, Edwin Delgado, se abordaron posibles soluciones para afrontar la problemática de hacinamiento por la que atraviesa el centro carcelario. Según cifras entregadas por el Director del Centro Penitenciario de Tunja, la unidad carcelaria cuenta con una población aproximada de 232 internos, lo cual excede la capacidad de la que dispone que es de cerca de 120 internos, lo que corresponde a una sobrepoblación aproximada del 85\%. “La razón del hacinamiento obedece principalmente a la población sindicada, ya que tenemos 80 internos sindicados que con la aplicación de la ley 1760, quedarían en libertad", explicó Edwin Delgado.
} 
el nivel de hacinamiento y ii) apoyo de los alcaldes del departamento de Boyacá en la revisión de los contratos interadministrativos.

En lo que concierne a la salud, mediante respuesta No. 149-EPMSCTUN-SAN 0812 de 02 de mayo de 2016, se halló que el Establecimiento Penitenciario de Mediana Seguridad y Carcelario de Tunja cuenta con el personal del área de sanidad con disponibilidad: i) un médico general, ii) odontóloga, iii) auxiliar de enfermería y iv) enfermera profesional

Todo este tipo de acciones médicoasistenciales repercute principalmente en el cumplimiento de la normatividad contemplada en el Decreto 2245 de 2015, en el que la USPEC celebró el contrato de Fiducia Mercantil 363 de 2015, con el consorcio Fondo de Atención PPL 2015, integrado por la Fiduprevisora y Fiduagraria S.A., para la administración y pagos de los recursos del Fondo de atención en salud para PPL, que incluso para el escenario penitenciario y carcelario de Tunja, se contrató la prestación de servicios profesionales con personas naturales, a fin de atender la prestación médico-asistencial de baja complejidad dentro del penal, como también la atención extramural de mediana y alta complejidad, a través del envío de cartas de invitación a diferentes hospitales y centros de salud, priorizando los centros de referencia de la PPL.

Sin embargo, mediante informe de la Procuraduría General de la NaciónPresidencia de la República y Defensoría del Pueblo (2016), por medio del cual se adopta el primer informe semestral de seguimiento a la Sentencia T-762 de 2015, se identificaron como problemática estructural al sistema de salud del sector penitenciario y carcelario los siguientes hallazgos frente al particular:

i) Frente a la atención en salud intramural, a partir del 09 de mayo de 2016, no se contaba con médico intramural, arrojando la carencia de personal en salud, en el EPMSC de Tunja (Procuraduría General de la
Nación-Presidencia de la República y Defensoría del Pueblo, 2016, p. 30).

ii) Dentro del contenido de este informe se aprecia, que en cuanto al cumplimiento para la prestación de los servicios de salud a la PPL, según la información proveniente de 136 establecimientos de reclusión, 74 no contaban con stock de medicamentos para suplir las necesidades de los internos, incluido el EPMSC de Tunja (Procuraduría General de la Nación, Presidencia de la República y Defensoría del Pueblo, 2016, p. 32).

iii) En relación con los insumos médicos y odontológicos requeridos, 114 de los 136 reportaron no tener disponibilidad de insumos suficientes para brindar la atención en salud a los internos, incluido el establecimiento penitenciario, objeto de estudio (Procuraduría General de la Nación, Presidencia de la República y Defensoría del Pueblo, 2016, pp. 32-33).

iv) En lo que respecta a la recolección de residuos hospitalarios, como criterio importante en la prestación de servicios de salud referente a las áreas de sanidad de los establecimientos de reclusión, se llevó a cabo el seguimiento de este criterio, y se evidenció que de acuerdo con la información suministrada por los 136 establecimientos, 122 no contaban con servicio de recolección de residuos hospitalarios (Procuraduría General de la Nación, Presidencia de la República y Defensoría del Pueblo, 2016, pp. 33-34). En tercer lugar, el EPMSC de Tunja, para 2017, llevó a cabo un diagnóstico de la situación de derechos humanos por parte del INPEC frente al hacinamiento penitenciario, en el cual el grupo Diagnósticos DDHH, Unidos por los Derechos Humanos, Grupo de Derechos Humanos, Dirección General INPEC (2017) obtuvo lo siguiente como resultado frente al establecimiento: 
Tabla 1. Diagnóstico de la situación de Derechos Humanos

\begin{tabular}{|c|c|c|c|c|c|c|c|c|c|c|}
\hline FECHA & $\begin{array}{c}\text { TOTAL } \\
\text { POBLACIÓN }\end{array}$ & HACINAMIENTO & \multicolumn{2}{|c|}{ SEXO } & \multicolumn{2}{|c|}{ SINDICADOS } & $\begin{array}{c}\text { TOTAL } \\
\text { SINDICADOS }\end{array}$ & \multicolumn{2}{|c|}{ CONDENADOS } & $\begin{array}{c}\text { TOTAL } \\
\text { CONDENADOS }\end{array}$ \\
\hline $\begin{array}{l}\text { Enero de } \\
2016\end{array}$ & 222 & $85,0 \%$ & 222 & 0 & 59 & 0 & 59 & 163 & 0 & 163 \\
\hline $\begin{array}{l}\text { Marzo de } \\
2016\end{array}$ & 234 & $95,0 \%$ & 234 & 0 & 54 & 0 & 54 & 180 & 0 & 180 \\
\hline $\begin{array}{l}\text { Abril de } \\
2016\end{array}$ & 234 & $95,0 \%$ & 234 & 0 & 57 & 0 & 57 & 177 & 0 & 177 \\
\hline $\begin{array}{l}\text { Julio de } \\
2016\end{array}$ & 213 & $77,5 \%$ & 213 & 0 & 51 & 0 & 51 & 162 & 0 & 162 \\
\hline $\begin{array}{l}\text { Agosto de } \\
2016\end{array}$ & 218 & $81,7 \%$ & 218 & 0 & 50 & 0 & 50 & 168 & 0 & 168 \\
\hline $\begin{array}{l}\text { Septiembre } \\
\text { de } 2016\end{array}$ & 222 & $85,0 \%$ & 222 & 0 & 55 & 0 & 55 & 167 & 0 & 167 \\
\hline $\begin{array}{l}\text { Octubre } \\
\text { de } 2016\end{array}$ & 222 & $85,0 \%$ & 222 & 0 & 48 & 0 & 48 & 174 & 0 & 174 \\
\hline
\end{tabular}

Fuente: Instituto Nacional Penitenciario y Carcelario, 2017, p. 28.

A partir de lo anterior, se concluyó que dentro del EPMSC de Tunja se han albergado alrededor de 223 PPL, de las cuales aproximadamente 53, es decir, el $24 \%$ son sindicadas, y 171 , es decir el $76 \%$, son condenadas, y que en promedio tiene un hacinamiento del $86.2 \%$ (Diagnósticos DDHH, Unidos por los Derechos Humanos, Grupo de Derechos Humanos, Dirección General INPEC, 2017, pp. 28-29).

Dadas las condiciones que anteceden, se evidencia que aunque la salud en favor de la PPL aparece mayoritariamente relacionada a los DESC, como una política pública del Estado sobre esa población en específico (modelo de atención en salud para la PPL), no se debe descuidar que el rol de los DDHH en el escenario del derecho internacional, faculta el derecho a la salud a un rango de carácter fundamental, con personalidad propia y sujeta a una protección jurídica particular, que incluso ha dado lugar a que las altas cortes, intervengan en la materialización y protección de los derechos fundamentales de rango constitucional y supraconstitucional a la población privada de la libertad.

Para el escenario del EPMSC de Tunja, se ha garantizado como institución el cumplimiento de la pena privativa de la libertad, la detención precautelativa, la seguridad, la atención social y el tratamiento penitenciario de la población reclusa, en el marco de los DDHH, y que se ha visto 
Protección y reconocimiento institucional y jurisprudencial del derecho humano a la salud en el establecimiento penitenciario de Tunja

limitada a garantizar el goce efectivo de los derechos de la PPL, en relación con la existencia y la disponibilidad de recursos materiales y humanos, para efectivizar el amparo a la salud; no obstante, a pesar de la sobrepoblación carcelaria como factor de determinante social, la administración y la prestación de los servicios de sanidad y asistencial es asequible, accesible e idónea, tomando en cuenta que existen los recursos técnicos, logísticos y administrativos -sea mucho o poco- el rubro presupuestal que se asigne por parte de la USPEC, en el que se busca en últimas, la equidad y reciprocidad en brindar a la población tanto condenada como sindicada, la protección y reconocimiento de sus derechos fundamentales, como mejora continua de las condiciones de existencia de este sector poblacional.

En cuarto lugar, mediante Oficio No. 8300-DIRAT de fecha 09 de abril de 2019, se establece que el EPMSC de Tunja cuenta actualmente con 206 internos con medida intramural, de los cuales el $100 \%$ de los internos cuenta con cobertura en salud:

\section{Tabla 2. Número de internos y régimen de afiliación}

\begin{tabular}{|l|c|}
\hline \multicolumn{1}{|c|}{$\mathbf{N}^{\circ}$ de internos } & Régimen de afiliación \\
\hline $183 \mathrm{PPL}$ & Fondo Nacional de Salud \\
\hline $19 \mathrm{PPL}$ & Régimen Contributivo \\
\hline $4 \mathrm{PPL}$ & Régimen Especial o de Excepción \\
\hline
\end{tabular}

Fuente: Elaboración propia con base en Oficio 8300DIRAT de fecha 09 de abril de 2019 - Dirección de Atención y Tratamiento del INPEC.

El establecimiento penitenciario cuenta con 189 internos en estado de detención o prisión domiciliaria, los cuales tienen con la siguiente afiliación en salud:

Tabla 3. Número de internos en detención o prisión domiciliaria y régimen de afiliación

\begin{tabular}{|l|l|}
\hline $\begin{array}{c}\mathbf{N}^{\circ} \text { de internos en estado de } \\
\text { detención o prisión domiciliaria }\end{array}$ & $\begin{array}{c}\text { Régimen de } \\
\text { afiliación }\end{array}$ \\
\hline $\begin{array}{l}103 \text { internos en estado de } \\
\text { detención o prisión domiciliaria }\end{array}$ & $\begin{array}{c}\text { Régimen } \\
\text { subsidiado }\end{array}$ \\
\hline
\end{tabular}

\begin{tabular}{|l|c|}
\hline \multicolumn{1}{|c|}{$\begin{array}{c}\mathbf{N}^{\circ} \text { de internos en estado de } \\
\text { detención o prisión domiciliaria }\end{array}$} & $\begin{array}{c}\text { Régimen de } \\
\text { afiliación }\end{array}$ \\
\hline $\begin{array}{l}48 \text { internos en estado de } \\
\text { detención o prisión domiciliaria }\end{array}$ & $\begin{array}{c}\text { Fondo Nacional } \\
\text { de Salud PPL }\end{array}$ \\
\hline $\begin{array}{l}34 \text { internos en estado de } \\
\text { detención o prisión domiciliaria }\end{array}$ & $\begin{array}{c}\text { Régimen } \\
\text { Contributivo }\end{array}$ \\
\hline $\begin{array}{l}4 \text { internos en estado de } \\
\text { detención o prisión domiciliaria }\end{array}$ & $\begin{array}{c}\text { Régimen } \\
\text { Especial o de } \\
\text { Excepción }\end{array}$ \\
\hline
\end{tabular}

Fuente: Elaboración propia con base en Oficio 8300DIRAT de fecha 09 de abril de 2019 - Dirección de Atención y Tratamiento del INPEC.

De todo esto se desprende que la cobertura y el alcance de afiliación del derecho humano a la salud para la PPL, ubicada en el municipio de Tunja, presenta y brinda un acompañamiento técnico satisfactorio a partir de la dirección de atención y tratamiento del INPEC, en colaboración y solidaridad por gestiones de intervención con secretarías de salud del orden departamental y municipal, en lo concerniente al Plan de Intervenciones Colectivas (PIC), a través de la suscripción de convenios interinstitucionales relacionados principalmente al manejo de la salud pública en los centros penitenciarios.

De igual manera, como escenario de acompañamiento y solidaridad social, se tiene presente el rol de la Alcaldía Mayor de Tunja y la Secretaría de la Mujer (2017, pp.1-3), para el primer semestre de 2017, mediante el informe de gestión "Mi Oportunidad", se aprecia la realización de atención psicosocial de cinco personas privadas de la libertad con su núcleo familiar, como también la actualización de la base de datos de 76 PPL de Tunja, en la cárcel distrital EPMSC de Tunja.

Al mismo tiempo, el procedimiento de valoración médica de ingreso de una PPL al establecimiento penitenciario, requiere principalmente de los siguientes aspectos:

i) En el marco del artículo 45 de la Ley 1709 de 2014, define el examen de ingreso y egreso, que consiste que al momento de ingresar un procesado o condenado al centro de reclusión se 
le abrirá el correspondiente registro en el sistema de información de Sistematización Integral del Sistema Penitenciario y Carcelario (SISIPEC).

ii) La PPL deberá ser sometido a examen médico, con el fin de verificar el estado físico, patologías y demás afecciones para la elaboración de la ficha médica correspondiente.

Sobre este último punto, se debe tener en cuenta que la Subdirección de Atención en Salud/ Grupo de Salud Pública del INPEC implementó a nivel nacional, el procedimiento para la realización del Examen Médico de Ingreso (EMI), cuyo objetivo es establecer las actividades, que permitan evidenciar el estado físico, mental y las patologías concomitantes, para identificar eventos de interés en salud pública, la promoción de la salud y la prevención de la enfermedad, la detección precoz, la demanda inducida a los servicios y determinar las necesidades de atención en salud, contibuyendo a la estrategia de gestión del riesgo en salud, y como puerta de entrada al modelo de atención en salud con enfoque de atención primaria, al ingreso de las PPL, a los Establecimientos de Reclusión del Orden Nacional (ERON), a cargo del INPEC.

Como seguimiento de esta actividad de acceso al derecho a la salud, se debe resaltar que hasta 2009 el INPEC fue el prestador principal de los servicios de salud de la PPL, fecha a partir de la cual fue asumida por Caprecom E.P.S. (hasta diciembre de 2015) y desde esta última fecha, el ejercicio de la contratación de la prestación de los servicios de salud para la PPL, a cargo del INPEC, está bajo la responsabilidad del consorcio Fondo Nacional de Salud PPL 2019, entidad contratada por la Unidad de Servicios Penitenciarios (USPEC).

En sede judicial se destacan las actuaciones administrativas y de logística llevadas a cabo por el EPMSC de Tunja, frente a una PPL de la tercera edad, y su exoneración de responsabilidad administrativa por falla en el servicio, por la causal de falta del nexo causal.
Frente a este tema particular, la sentencia de primera instancia del Juzgado Catorce Administrativo Oral del Circuito de TunjaSentencia de 21 de noviembre de 2018 -Rad. 15001-33-33-014-2014-00124-00- Medio de Control: Reparación Directa (2018), con ponencia del juez Javier Humberto Pereira Jauregui, sostuvo lo siguiente.

i) Persona de la Tercera Edad - PPL: el señor Fabriciano Espinel Cepeda ingresó al EPMSC de Tunja, el 28 de mayo de 2012, quedando bajo la custodia del Estado, por estar sujeto, a una medida de privación de la libertad, con 82 años de edad, padeciendo de enfermedades crónicas (diabetes, hiperuricemia, artritis reumatoide degenerativa, hipertensión arterial, HTA, úlceras, pérdida aguda visual y arritmia cardiaca), las cuales fueron tratadas y controladas durante los años 2012 y 2013, por el servicio médico del penal. En esa medida, el interno al ingresar al penal tenía una edad muy avanzada, y adicionalmente, con esa serie de enfermedades era evidente que su expectativa de vida no era la mejor, causando su deceso natural el 16 de julio de 2013.

ii) Servicio Médico del EPMSC de Tunja: se brindó al señor Fabriciano Espinel Cepeda la prestación de los servicios médicos y asistenciales entre 2012 y 2013, a través de los médicos del área de sanidad y de Caprecom E.P.S, con base en los lineamientos del modelo de atención en salud para la PPL, teniendo en cuenta la Resolución 5159 de 2015, laborando jornadas de mañana y tarde de lunes a viernes, teniendo la disponibilidad tambien los fines de semana.

Adicionalmente, frente a la PPL con condición de la tercera edad, se llevaron a cabo las siguientes funciones:

a) La asignación de una enfermera y un coordinador de salud escogido por el Comité del Centro Penitenciario, suministrando los medicamentos ordenados por el médico tratante; 
b) La atención extramural para el servicio de especialidades, procedimientos y exámenes médicos;

c) La no demora en la expedición de autorizaciones y exámenes;

d) Atención constante por medicina general, al ser un paciente con enfermedades de control (diabetes, hiperuricemia, artritis reumatoide degenerativa, hipertensión arterial, HTA, úlceras, pérdida aguda visual y arritmia cardiaca).

e) Atención preferencial en comparación con otros internos, acudiendo directamente al servicio de salud, sin la necesidad de solicitar cita previa.

f) Recepción y atención del especialista en medicina interna.

g) Procedimiento y aplicación de insulina.

h) Control y manejo nutricional cada dos meses, acreditando minuta especial en la preparación de alimentos en el Rancho del EPMSC de Tunja.

iii) Decisión sobre la falta del nexo causal: el Despacho sostuvo la tesis sobre el hecho de que si bien se acreditó el daño antijurídico, no se probó la acción u omisión imputable al Estado y. por tanto, el tercer elemento de la responsabilidad, que consiste en la existencia del nexo causal entre el daño y la acción u omisión del Estado; no se configuró, toda vez que el INPEC-EPMSC de Tunja y Caprecom E.P.S. dieron cumplimiento a un deber legal de prestar los servicios de salud a la PPL, señor Fabriciano Espinel Cepeda, recibiendo el tratamiento médico prescrito para el padecimiento de sus multiples enfermedades y conforme a los protocolos médicos, por lo cual se concluye el resultado de su deceso fue por muerte natural (caso fortuito súbito), y no un mal manejo médico que se haya dado.
Tomando en cuenta lo anterior, frente al rol del INPEC a través del EPMSC de Tunja, se genera indispensablemente un alcance fundamental al derecho a la salud en favor de la PPL, sin importar la condición de la PPL, por cuanto hay lugar a la disponibilidad, asequibilidad, cobertura y asistencia de los servicios asistenciales, que se producen principalmente en cuatro características como son:

i) un enfoque diferencial y aplicado en la organización en la prestación del servicio, ii) la integralidad de las acciones, iii) la orientación de las actividades de salud, iv) la gestión de los riesgos en salud de dicha población, incluyendo funciones asistenciales y logisticas, $\mathrm{y}$ v) la operacionalización de fases de la prestación de los servicios de salud (promoción - prevención - diagnóstico - tratamiento y rehabilitación de la enfermedad);

Del último ítem, se deduce que siempre y cuando esta última exista en el rubro presupuestal y de sostenibilidad para esta población, como también de la regulación de la sobrepoblación carcelaria; debido a que se requiere de la destinación económica para la contratación de personal médico, suministro de medicamentos y servicios médicos indispensables como la odontología, la medicina general y la enfermería, puesto que en última instancia, la salud requiere en esencia de la cobertura, la continuidad y la atención prioritaria para la garantía y el goce efectivo de los DDHH de las PPL.

\section{Visión de los organismos de control humanitario y administrativo frente al EPMSC de Tunja}

\section{Personería Municipal de Tunja - Delegatura para los DDHH}

El papel de la Personería Municipal de Tunja, a través de la delegatura para los DDHH, se identifica principalmente en el funcionamiento, participación, protección, 
promoción, guarda y reconocimiento en pro de las comunidades más vulnerables, especialmente en la atención para la población reclusa localizada en el EPMSC de Tunja.

Sobre el particular, mediante informe de la Personería Municipal de Tunja (2016, p. 58), comprendido entre marzo a diciembre de 2016, se llevó a cabo la garantía de aplicación del debido proceso en el momento de la calificación de conducta y consejo de disciplina, como prerrequisito para solicitar la libertad de la PPL, así como también esa delegatura hace parte integrante del comité de derechos humanos, en donde se hace visita dos veces al mes al EPMSC de Tunja, para la vigilancia relacionada con i) atención en salud, ii) alimentación, iii) habitabilidad, iv) asesoría jurídica, v) deporte, entre otros. La cárcel tiene una capacidad para 120 internos, en promedio cuenta con 240 internos; es decir, que existe un hacinamiento del $100 \%$.

Dentro de ese periodo, se ejercieron actividades como: i) socialización de comités efectuados por la procuraduría provincial de Tunja, a través de los cuales convocó a las entidades territoriales para brindar apoyo económico al INPEC; y ii) suscripción de convenio interinstitucional entre el INPECEPMSC de Tunja y el municipio, para la adquisición de un vehículo para el traslado de PPL (Personería Municipal de Tunja, 2016, p. 59).

En segundo lugar, mediante la realización de entrevista a la personera delegada para los derechos humanos a la doctora Sandra Liseth Piña Ávila, en 2017, se identificaron los siguientes hallazgos relacionados a la protección de los DDHH, de este sector poblacional:

- El EPMSC de Tunja tiene una población carcelaria pequeña, cuya sobre población penitenciaria es de 232 PPL, y destinada principalmente para una población de 120 PPL, en donde el actuar de la Personería Municipal de Tunja es brindar apoyo y velar por el derecho fundamental a la salud de los internos.
- El conocimiento de los casos de vulneración de DDHH, tanto en Tunja, como a nivel nacional, en los establecimientos penitenciarios, se manejan a través de dos comités, como son: i) El Comité de Derechos Humanos y ii) el Comité Disciplinario. Frente al primero, hay tres representantes de los internos que dan a conocer los casos de sus compañeros que no han sido atendidos, y que tienen alguna cita médica pendiente con especialista que requieren una valoración, por lo cual ante dichas problemáticas, la personería municipal actúa exigiendo a las E.P.S brinde la atención asistencial, lo cual para la PPL, se tiene un manejo especial por parte del INPEC $y$, localmente, el EPMSC de Tunja, cuenta con un funcionario encargado-médico, que dentro de sus obligaciones se establece atender asistencialmente a la PPL, para efectos de llevar a cabo posteriormente la autorización de traslado, el agendamiento de citas, el personal de guardia, y especialmente el acompañamiento a los casos particulares que se presenten por la salud de la PPL.

Efectivamente, como Personería y como Ministerio Público, dentro de la misión constitucional, de promoción, defensa y protección de los DDHH, se realiza acompañamiento no solo a la población carcelaria; sino, a la población vulnerable, en donde sus derechos fundamentales estén brindándose de manera efectiva. En el escenario de la cárcel se trabaja desde varias ópticas, una de ellas como Ministerio Público dentro del debido proceso que se adelanta en el proceso penal (dos delegados en asuntos penales), y frente a las PPL, se le hace el seguimiento y acompañamiento para velar sus derechos en tres escenarios:

i) Que la atención en el establecimiento sea digna;

ii) Que los funcionarios o el personal de guardia no le falten al respeto a la PPL, como también de esa misma población hacía los guardias y dragoneantes, situación conflictiva que 
se tiende a asumir herramientas como la presentación de informes para abrir procesos disciplinarios, en el evento de que la PPL alteren el orden y la disciplina dentro del penal;

iii) Frente al Comité se Derechos Humanos se habla de cuatro pilares fundamentales dentro del EPMSC de Tunja, a saber.

a) La habitabilidad: se hace entrega de una colchoneta digna a la PPL, en un espacio adecuado en donde las celdas haya un mínimo de personas, para combatir el tema de hacinamiento, donde el ideal es que una celda sea para dos personas; por ende, el establecimiento realiza jornadas de aseo con el propósito de sacar cosas en donde los internos ya no necesitan, como por ejemplo, hay internos que tienen cuatro cobijas, cuando en una celda solo se requiere de una cobija, además del exceso de ropa, vestuario, y calzado. Este punto es fundamental en la socialización del Comité de DDHH, dado que la PPL a través de sus representantes, puede considerar y sentar de presente, la carencia o falta de una colchoneta.

b) Salud: en el Comité de DDHH se tocan temas relacionadas a demoras injustificadas por parte de la atención a un interno, falta del suministro de medicamentos, toma de exámenes médicos, citas con especialistas y urgencias, por lo que la prestación del servicio es inmediata y prioritaria por parte del EPMSC de Tunja, teniendo en cuenta que en el municipio de Tunja hay cinco centros hospitalarios para atender las patologías que acaecen la PPL, al punto que los remiten para atender y garantizar sus condiciones de existencia.

c) Alimentación: se verifica la minuta establecida por el USPEC, correspondiente a 18 menús (desayuno, almuerzo y comida), resaltando que los días de visita, sábados y domingos, las PPL tienen su menú normal y a la visita que ingresa comida, siempre se le hace claridad que el menú es de la visita. Asimismo, tienen una especie de caspete, donde pueden comprar alimentos comestibles para la visita de familiares de los internos, los fines de semana.

d) En el tema de jurídica, a las PPL se les entrega la calificación de conducta o si tienen alguna comunicación, se les debe notificar, en relación con procesos judiciales o de cualquier otra índole; por ello, la personería municipal de Tunja, asume un rol participativo y de solidaridad social en el comité de DDHH, atendiendo con conocimiento de causa la recepción de cualquier tipo de queja, solicitud o denuncia que se presente dentro del penal, en especial a situaciones de incumplimiento y/o desmejora en sus condiciones.

En lo que respecta a la prestación del servicio médico y asistencial, el EPMSC de Tunja cuenta con un personal médico y de odontología, funcionarios que se encargan en la parte interna del establecimiento penitenciario en pro de la PPL, y evidenciando que el alcance se logra con base a la agilidad en el sistema de salud penitenciaria (modelo de atención en salud), a fin de superar el retardo injustificado y la demora de asignación de citas médicas y especializadas, finalización de contratos y falta de suministro de medicamentos, por lo cual la acción de la Personería Municipal es identificar y determinar la necesidad de la queja por parte de la PPL, que incluso, en caso de no darse cumplimiento a la prestación del servicio asistencial, se iniciaría un informe con las situaciones de facto y jurídicas que se presenten, y se presentaría ante el Comité de DDHH y a la Oficina de Control Interno del EPMSC de Tunja, para la evaluación del caso de la PPL; como también, la interposición de acciones constitucionales como la tutela por protección al derecho fundamental a la salud.

Igualmente, se trabaja mancomunadamente con el establecimiento, la realización de jornadas de cedulación, salud para monturas, cajas de dentadura y se trata de vincular a las jornadas que ofrece el establecimiento, como es el mes de la mercedes y el día de los niños; en este último, la Personería Municipal de Tunja, a través de sus funcionarios, hacen recolecta para llevar y realizar una jornada a los hijos 
de los internos, como también la gestión con las entidades del municipio para celebrar el Día de las Mercedes.

En cuanto al municipio, se rindió informe ante el Concejo Municipal de las actividades realizadas por la entidad, así como de la problemática en este centro de reclusión, colocando de presente que los costos económicos y de sostenibilidad de la PPL, en calidad de condenados. Efectivamente los asume directamente el INPEC, a través de un modelo de atención en salud, de régimen especial; mientras que la PPL, en calidad de sindicados, los debe asumir el Municipio de Tunja, dado que este sector poblacional no ha tenido un fallo condenatorio, lo cual se aconsejó en esa oportunidad, la necesidad de acciones administrativas como la suscripción de convenios interinstitucionales con el INPEC, frente a la regulación de este sector poblacional.

Frente a casos especiales de PPL por sus condiciones de salud, el Comité de DDHH y la Personería Municipal de Tunja evidenciaron la importancia de atención a este tipo de casos que se presenten con la PPL, como fue la atención a 12 personas con dieta especial con sugerencias de preparación al administrador del rancho, por padecer enfermedades de hipertensión, diabetes, personas con VIH y la atención prioritaria a personas de la tercera edad privadas de la libertad, mayores a 70 años, por condiciones de desmejora física $\mathrm{y}$ de salud, que han solicitado la casa por cárcel-prisión domiciliaria.

\section{Defensoría del Pueblo - Regional Boyacá}

La Defensoría del Pueblo - Regional Boyacá como organismo autónomo y veedor de los DDHH y del DIH, en el territorio tunjano, evaluó el impacto de la condición penitenciaria y carcelaria en el EPMSC de Tunja, con corte a febrero de 2019, y surtiéndose el instrumento de entrevista frente a esta entidad, en donde se obtuvieron los siguientes aspectos, aportes y resultados, frente al particular:
En primer lugar, con respecto al estudio de protección y reconocimiento del derecho a la salud en PPL, en el EMPSC de Tunja, la Defensoría del Pueblo como autoridad y organismo de control de los DDHH ha realizado capacitaciones en promoción, defensa y divulgación de los $\mathrm{DDHH}$, por parte del personal profesional en derecho (defensores públicos - programa $1542 \mathrm{y}$ funcionarios adscritos a la regional), en especial sobre la exigibilidad del derecho humano a la salud a través de los mecanismos de protección como la tutela y amparados por los Despachos Judiciales.

En segundo lugar, la Defensoría del Pueblo hace acompañamiento y atención social en defensa de las PPL, realizándose a través de visitas constantes al EPMSC de Tunja, con el objeto de verificar las condiciones en que se encuentran y sí se está cumpliendo con las garantías a sus derechos fundamentales, como son la atención en salud, alimentación, alojamiento, trabajo, estudio y hacinamiento

En tercer lugar, desde la óptica de los DDHH, en relación con el modelo de atención en salud para la PPL, frente a los profesionales que prestan los servicios de salud y sanidad, principalmente se encuentran contratados directamente por un prestador en salud denominado La Fiduprevisora, que fue contratada por la USPEC con base al Fondo Nacional de Salud de las PPL, creado bajo la Ley 1709 de 2014 y suscrita con el Consorcio Fondo de Atención en Salud PPL 2015 (integrado por las Sociedades Fiduprevisora S.A. y Fiduagraria S.A.) y el Contrato de Fiducia Mercantil 363 de 2015.

A partir de esta creación, la USPEC es la entidad encargada que maneja los recursos para contratación de servicios en los establecimientos penitenciarios y carcelarios del país, es decir que las únicas labores encaminadas a la prestación de estos servicios son:

i) La verificación o vigilancia directa por parte de la Fiduprevisora S.A. con base en la información suministrada por el EPMSC de Tunja. 
ii) La recepción de denuncia, queja o petición presentada por la PPL.

iii) El cumplimiento de órdenes judiciales emitidas por los jueces y magistrados en sus correspondientes despachos, una vez hayan interpuesto las acciones constitucionales correspondientes, en donde la Defensoría del Pueblo revisa el trámite procedimental establecido en la Resolución 5159 de 2015, a fin de verificar y sancionar la posible existencia y/o vulneración del derecho humano a la salud a la PPL.

En cuarto lugar, se hacen visitas relacionadas a campañas de salud, higiene y salubridad al interior de los establecimientos penitenciarios y carcelarios de Boyacá, con el debido acompañamiento de delegados de la Secretaría de Salud, quienes son los competentes en verificar las instalaciones; $\mathrm{y}$, posteriormente, hacer las respectivas recomendaciones al director del EPMSC, para que se tomen los correctivos en procedimiento y manipulación en la prestación de los servicios asistenciales y alimentarios, como también a la entidad prestadora de los servicios de salud, como lo es la Fiduprevisora S.A.

En quinto lugar, frente a la exigibilidad y garantía del derecho fundamental a la salud de las PPL y la conexión con los procedimientos, alcance y participación de organismos institucionales, se debe mencionar que las entidades competentes como el INPEC, los hospitales o centros especializados y el municipio de Tunja, les corresponde a través de su radio de acción las funciones de protección a la población carcelaria, en tres aspectos:

a) El Instituto Nacional Penitenciario y Carcelario (INPEC), le corresponde el traslado de aquellos privados de la libertad que requieren de una atención en salud de manera urgente.

b) A los hospitales o centros especializados les corresponde en brindar la atención que requiera el privado de la libertad como son citas con el especialista, servicio de urgencias, toma de radiografías, suministro de medicamentos, medicina general $\mathrm{y}$ cirugías (Hospital San Rafael, Clínica Santa Teresa, Clínica Medilasser, E.P.S.).

c) El municipio de Tunja celebra convenios interinstitucionales con el Instituto Nacional Penitenciario y Carcelario (INPEC), donde la entidad territorial debe aunar esfuerzos y de apoyo anual sobre ayudas con elementos indispensables para la población privada de la libertad, como son colchonetas y kits de aseo.

En sexto lugar, la Defensoría del Pueblo ha realizado el acompañamiento $\mathrm{y} / \mathrm{o}$ seguimiento a las distintas novedades que se presentan, pero que no se ha tenido reportes de casos relevantes o delicados con la salud de la PPL del EPMSC de Tunja.

No obstante, cabe señalar que la Defensoría del Pueblo, al ser ente vigilante de los DDHH, en cuanto a la salud, denota el alcance prestacional de este derecho, al punto que la garantía complementaria a la afiliación al sistema de seguridad social en salud de los internos, lo asume la Fiduprevisora, en su gran mayoría; como también las mismas PPL, directamente asumen su afiliación a prestadores de salud. Para el caso de las PPL, que se les conceden el beneficio de detención domiciliaria o libertad condicional, debe asumirlo por cuenta propia, o a través del municipio de Tunja, mediante el Sistema de Identificación y Selección de Potenciales Beneficiarios de Programas Sociales (SISBEN), si la PPL vive y reside dentro de esta jurisdicción territorial.

Respecto a la alimentación, la USPEC saca mediante proceso de licitación, el contrato para la prestación del servicio de alimentación, donde es asumido por una empresa particular, que se encarga de la preparación, calidad y suministro de los alimentos a las PPL. Relacionado con el acceso al agua potable, es asumido directamente por el INPEC, existiendo siempre un rubro para el pago y cancelación de este servicio, el cual ha sido excelente 
frente a la calidad y puntualidad en el acceso; empero para 2018, se tuvo conocimiento, por parte de la Defensoría del Pueblo, de una situación de suministro de agua potable, por el rompimiento en el sector de un ducto, pero la empresa de servicios de agua (VEOLIA), subsanó dicha anomalía de manera inmediata con el fin de restablecer el servicio.

Frente a la visita conyugal e integración familiar, la Ley 65 de 1993, modificada por la Ley 1709 de 2014, estipuló el derecho que tiene las PPL, para acceder a la visita tanto conyugal como familiar; y en ese evento, el EPMSC de Tunja ha garantizado ese derecho cada ocho días. Entre tanto, en lo concerniente a la habitabilidad, por ser la infraestructura física del EPMSC de Tunja, de forma "pequeña", solo existen dos alojamientos, donde son ubicados la totalidad de los PPL y que a corte de febrero de 2019 asciende a 215 PPL; sin embargo, se aclara que los altos índices de personas capturadas en los últimos años, el hacinamiento o sobrepoblación se ha incrementado, afectando de forma considerable la convivencia de las PPL en horas de la noche.

En séptimo lugar, el determinante social que ha marcado el fenómeno del hacinamiento carcelario es la falta de una verdadera reforma a la ley penal, pues con el sistema actual se ha incrementado el número de PPL. Es de anotar que el EPMSC de Tunja es uno de los establecimientos penitenciarios y carcelarios menos hacinados del país, en comparación con otros ERON, donde los espacios son pequeños para el alojamiento de un gran número de personas y debiendo turnarse para descansar en cada celda (algunos establecimientos de la Costa, Bogotá y URI de la Capital).

Por otra parte, la Fiduprevisora, como prestador de salud ha solventado la atención oportuna, asistencial y médica de las PPL en el EPMSC de Tunja, donde a la fecha no se han presentado inconvenientes frente a la prestación del servicio; pero, como Defensoría del Pueblo se exige -a través de los mecanismos constitucionales como el derecho de petición y tutela- el alcance prestacional y de atención en salud requerida para esta población en particular; por lo cual también se debe anotar que una vez la persona recobre su libertad y sale del EPMSC de Tunja, debe asumir por cuenta propia la atención en salud, o acudir ante la oficina asesora del SISBEN, para que sea ingresado y asumido por el municipio de Tunja.

En octavo lugar, desde el contexto de la solidaridad social, el acceso a la prestación de servicios médicos y asistenciales, la Defensoría del Pueblo a través del contexto institucional, encomendado por la Constitución Política de Colombia, tiene como finalidad principal de encaminar la defensa y protección de los derechos fundamentales de los ciudadanos, en especial a las personas privadas de la libertad, como grupo vulnerable. Igualmente, se resalta de forma importante que existen los fallos de la Corte Constitucional que ordenan al Ministerio Público, hacer seguimiento a las Sentencias T-388 de 2013 y T-762 de 2015, respecto del Estado de Cosas Inconstitucional en las cárceles del país, y que va encaminada a garantizar la totalidad de los derechos fundamentales de las PPL, seguimiento que se viene adelantando de manera mensual en cada uno de los 11 Establecimientos Penitenciarios del departamento de Boyacá.

En noveno lugar, mediante informe de visita de inspección por parte de la Defensoría del Pueblo con corte a finales de enero e inicios de febrero de 2019, en relación con el EPMSC de Tunja, se tiene los siguientes datos sobre las situaciones de goce efectivo de los DDHH, en especial la salud, así:

Frente a la salud de la población carcelaria de Tunja se tiene en cuenta la disponibilidad y prestación del personal médico y de sanidad, y la PPL diagnosticada con enfermedad grave en el establecimiento, por lo que se tienen como resultado los siguientes cuadros descriptores: 
Tabla 4. Disponibilidad y prestación del personal médico y de sanidad

\begin{tabular}{|l|l|l|c|c|c|}
\hline & \multicolumn{1}{|c|}{ Sí } & No & Cuántos & Horas al día & Días a la semana \\
\hline Médico general & $X$ & & 1 & 96 & 5 \\
\hline Psiquiatra & $X$ & & & & Régimen \\
\hline Odontólogo & $X$ & & 1 & 96 & 5 \\
\hline Ginecólogo & & $X$ & & & \\
\hline Pediatra & & $X$ & & & \\
\hline Obstetra & & $X$ & & & \\
\hline Psicólogo & & $X$ & & & \\
\hline Regente de Farmacia & & $X$ & & & \\
\hline Auxiliares de Enfermería & $X$ & & 1 & 192 & \\
\hline Otros & $X$ & & & & \\
\hline Cuáles: & \multicolumn{2}{|c|}{ Enfermera jefe y operadora de servicios generales (4 horas) } \\
\hline
\end{tabular}

Fuente: Informe de Inspección.Visita al EPMSC de Tunja de enero-febrero de 2019. Defensoría del Pueblo Regional Boyacá.

Tabla 5. Presencia de enfermedades y número de casos

\begin{tabular}{|l|c|l|c|}
\hline Enfermedad & Sí & No & Cuántos \\
\hline VIH & & X & \\
\hline Cáncer & & X & \\
\hline Diabetes & X & & 4 \\
\hline Hipertensión & X & & 27 \\
\hline Tuberculosis & & X & \\
\hline Trastornos Mentales & X & & 11 \\
\hline Insuficiencia Renal Crónica & & X & \\
\hline Varicela & & X & \\
\hline Cardiovasculares & & X & \\
\hline Infección Respiratoria Aguda & & X & \\
\hline
\end{tabular}

Fuente: Informe de Inspección.Visita al EPMSC de Tunja de enero-febrero 2019. Defensoría del Pueblo-Regional Boyacá.

De la anterior información señalada en los cuadros descriptores, se puede deducir que el personal médico que presta sus servicios en el EPMSC de Tunja cuenta con un médico general, un odontólogo y un auxiliar de enfermería, durante los cinco días de la semana, de manera permanente; mientras que temporalmente, se encuentra un psiquiatra, una enfermera jefe y la operadora de servicios generales, lo cual ha dado lugar a que el alcance de la prestación asistencial sea satisfactoria en pro de las PPL.

Por otra parte, con respecto a la población privada de la libertad, el mayor índice diagnosticado con enfermedad grave es la hipertensión con alrededor de 27 PPL, seguido de los trastornos mentales con 11 PPL y, por último, con cuatro PPL padeciendo diabetes, lo cual se sigue en su historial clínico, el seguimiento y el tratamiento de dichas patologías.

Dadas las condiciones que anteceden, concerniente a las instalaciones del área de sanidad del EPMSC de Tunja, se tiene la existencia de un consultorio médico, un consultorio odontológico, y un stock mínimo de medicamentos, más no se tiene una zona de atención prioritaria y un área de paso para monitorear a los reclusos que fueron hospitalizados, puesto que el EPMSC de Tunja, a través de sus funcionarios, remite a 
la población privada de la libertad a que sean atendidos en el Hospital San Rafael de Tunja. Vale la pena indicar que el EPMSC de Tunja cuenta con lo que se describe a continuación.

i) Espacios higiénicos.

ii) Un stock mínimo de medicamentos que son solicitados por el establecimiento con la cantidad requerida y de forma oportuna; sin embargo, se presenta por parte del proveedor del servicio, la tardanza en entregar los medicamentos en las fechas establecidas, como también no llegan la totalidad de lo requerido;

iii) Se cuenta con equipos e instrumentos para la atención médica general, pero en regular estado, debido a que no se ha realizado mantenimiento preventivo $\mathrm{y}$ correctivo.

iv) Disponibilidad y condiciones adecuadas de material para curación, insumos médicos y odontológicos que cuenta el establecimiento para prestar la atención en salud, que se encuentran almacenados en farmacia.

En relación con la situación de atención de urgencias para la población privada de la libertad, el EPMSC de Tunja, no cuenta con a) instrumentos y aparatos médicos; b) bala de oxígeno, c) equipos de reanimación. Únicamente se tiene como instrumento un concentrador de oxígeno y un equipo autoclave, por ende, frente a esta situación, las PPL que se encuentra en una grave situación de salud se remiten al Hospital San Rafael de Tunja.

Sobre el asunto de represamiento de citas médicas, procedimientos médicos, procedimientos odontológicos, remisiones de atención especializada y de red de operadores de servicios de salud para la atención especializada extramural de la PPL, se diagnosticó por parte de la Defensoría del Pueblo, que en el EPMSC de Tunja no se ha presentado represamiento de citas médicas. En lo relacionado a los demás aspectos, se tiene en cuenta lo siguiente:
Tabla 6. Decisiones médicas y cantidad de casos

\begin{tabular}{|l|c|c|c|}
\hline Categoría & Sí & No & Cuántos \\
\hline Procedimientos médicos & $X$ & & $2 \mathrm{PPL}$ \\
\hline $\begin{array}{l}\text { Procedimientos } \\
\text { odontológicos }\end{array}$ & $\mathrm{X}$ & & $23 \mathrm{PPL}$ \\
\hline $\begin{array}{l}\text { Remisiones de atención } \\
\text { especializada }\end{array}$ & $\mathrm{X}$ & & $20 \mathrm{PPL}$ \\
\hline $\begin{array}{l}\text { Red de operadores de } \\
\text { servicios de salud para la } \\
\text { atención especializada } \\
\text { extramural de la PPL }\end{array}$ & $\mathrm{X}$ & 27 \\
\hline
\end{tabular}

Fuente: Informe de Inspección. Visita al EPMSC de Tunja de enero-febrero de 2019. Defensoría del Pueblo-

Regional Boyacá.

De acuerdo con estas evidencias, se debe tener en cuenta y exigir a la PPL la afiliación al régimen contributivo o subsidiado según la capacidad de pago, e incluso para la PPL en detención domiciliaria, se requiere también de las constancias de las redes externas que prestan servicios de salud de nivel I, II y III, indicándose a qué distancia se encuentra del EPMSC de Tunja.

Como seguimiento a esta actividad prestacional a la salud de la PPL, el EPMSC de Tunja ha garantizado a los internos, la cobertura en i) la atención efectiva derivada de las autorizaciones de procedimientos con especialistas emitidas por el Fondo de Atención en Salud para la PPL, y por la red hospitalaria; ii) la garantía del traslado de manera oportuna por parte del personal de guardia a la PPL, para los procedimientos con especialistas autorizados por el Fondo de atención en salud; iii) la realización y recolección de desechos hospitalarios por parte de la empresa EDEPSA, con periodicidad de un mes; $y$ iv) se ha garantizado el $100 \%$ de cobertura en atención de primer nivel, así como también en los casos de complicación grave de la PPL, son remitidos al Hospital San Rafael.

Por último, respecto al ingreso de la PPL al EPMSC de Tunja, se evidenció por parte de la Defensoría del Pueblo que el procedimiento 
de ingreso se cumple a cabalidad en lo señalado en la ley y en los reglamentos, correspondiente a la realización de un examen integral de la PPL, sobre su estado de salud física, psicológica, y psiquiátrica, que se encuentra reportado en la historia clínica de cada PPL, como también se reporta novedad física y condición especial por parte del área de sanidad, a fin de respetar y resguardar su vida e integridad personal.

\section{SECRETARÍA DE SALUD DEPARTAMENTAL}

Mediante realización de entrevista llevada a cabo al secretario de salud departamental, Dr. Germán Francisco Pertuz, en 2019 se identificaron los siguientes aportes, hallazgos y resultados relacionados al seguimiento, alcance y protección de los derechos humanos de las PPL, en Tunja y el departamento de Boyacá, lo cual permite indicar la conducencia y la pertinencia sobre el campo de estudio de la investigación:

- En materia de acompañamiento y atención social relacionado a las PPL en el contexto tunjano, la Secretaría de Salud Departamental, bajo su competencia y mandato de la ley, tiene como función principal de verificar lo relacionado con a) saneamiento básico, b) potabilidad de agua, c) condiciones de saneamiento, d) condiciones higiénicas, y e) condiciones de los ranchos.

- Así mismo, la Secretaría de Salud Departamental, como autoridad sanitaria, revisa todo lo relacionado con la alimentación y comida de las PPL, haciendo control y seguimiento de visitas a los centros penitenciarios y carcelarios de Boyacá. También vigila que se lleve a cabo la toma de muestras de las palmas de las manos de los manipuladores de alimentos, de las superficies y de la calidad de la alimentación. Entre otras funciones, la Secretaría de Salud Departamental evalúa, diagnostica y verifica los brotes de, enfermedades transmitidas por alimentos (ETA) y por vectores.

- En ese mismo sentido, ante cualquier anomalía, queja, denuncia o petición relacionada con salud pública y saneamiento básico, se informa ante la Unidad de Servicios Penitenciarios y Carcelarios (USPEC) como a la Procuraduría Regional de Boyacá, acerca de las condiciones de los establecimientos penitenciarios y carcelarios de Boyacá, referente a la no mejora en la habitabilidad y de saneamiento básico ambiental, que incluso como autoridad ambiental, tiene la competencia de sellar los pabellones y de colocar una medida de cierre temporal, con el objetivo de que se hagan las respectivas adecuaciones. Un ejemplo fue el cerramiento y sellado del rancho del centro penitenciario y carcelario del Barne, en 2018, considerado como uno de los más grandes del departamento.

- A partir de este tipo de medidas, las autoridades del INPEC y USPEC intervienen de forma inmediata para contratar y cambiar el menaje, estufas, pisos, techos y superficies; a razón de ello, se han tenido problemáticas con los funcionarios de autoridad carcelaria, porque no han entendido que las personas privadas de la libertad que manipulan alimentos, tienen que tener un curso para realizar dicha actividad, se rotan con mucha frecuencia y que las mismas PPL que redimen con su trabajo, se benefician de reducciones de la pena. Es por ello, que la Secretaría de Salud Departamental tiene competencia de este tipo de eventos sanitarios y de saneamiento básico ambiental.

- Para el EPMSC de Tunja, en la última visita arrojó unas condiciones sanitarias favorables por encima del $75 \%$, donde se hacen visitas periódicas, específicamente dos veces al año, para seguimiento $y$ verificación de salud pública, así como también se recepciona queja, solicitud, reclamo y denuncia de alguna de las PPL, o si es directamente la solicitud por parte de los directores de los establecimientos penitenciarios, la función de la Secretaría de Salud Departamental es intervenir de forma inmediata con el equipo interdisciplinario con ingenieros de alimentos, ingenieros sanitarios y médicos, desplazándose hacia esos establecimientos, para lo pertinente frente a la materia y competencia, como son la toma de muestras de las manos, de las superficies, y de la revisión de las condiciones 
higiénico-sanitarias, con el fin de dictaminar mediante informe si se está cumpliendo a cabalidad lo relacionado a salud pública.

- Es de señalar que la enfermedad que tiene mayor impacto en los establecimientos penitenciarios de Boyacá es la tuberculosis, de modo que el tratamiento de las PPL que padecen de dicha patología y que del $100 \%$ de los casos detectados, el $100 \%$ tiene quimioterapia y correspondiente tratamiento. En Tunja no se ve tanto, porque la mayoría de las PPL que están en el establecimiento penitenciario son de Tunja, o de municipios aledaños, lo cual no ha generado brotes referenciadas a esa enfermedad.

- Con respecto a Caprecom E.P.S., el Gobierno Nacional le entregó a los establecimientos penitenciarios y la atención a las PPL a Caprecom E.P.S., y por conocimiento de causa, se presentaron en esa oportunidad acumulación de problemas tanto en la remisión de los pacientes PPL como en su atención, no tanto de que no existan contratos, sino que por ejemplo, para poder sacar a una PPL es todo un proceso, pasando por agendar una cita por médico especialista, la congruencia entre lo agendado y el día en que haya disponibilidad del guardia, transporte, $\mathrm{y}$ del personal que acompañe al interno.

- A razón de este procedimiento, Caprecom E.P.S ha tenido dificultades para la época de no remitir a tiempo a las PPL, para revisión, diagnóstico, toma de exámenes y chequeo médico, ocasionando consecuencias de pérdidas de cita, y de logística del INPEC.

- Es necesario hacer un llamado a la Unidad de Servicios Penitenciarios y Carcelarios - USPEC, en el deber de mejorar las condiciones de los servicios asistenciales y de salud de las PPL, especialmente y sobre todo en la oportunidad con los pacientes demandantes, que por el hecho de estar recluidos y confinados en los establecimientos penitenciarios, se observe y se dé un diagnóstico físico y mental antes, durante y después de estar insertado en los ERON.
- En lo que respecta a la afiliación al sistema de seguridad social en salud, se evoca el aseguramiento de la PPL, que le corresponde íntegramente al INPEC, asumir el $100 \%$ de la población reclusa independiente que tengan en su libertad, si tenían medicina prepagada, régimen contributivo, y régimen subsidiado; que una vez verificada la clase de afiliación que se encuentra y pase a ser persona privada de la libertad, a cargo del INPEC, corren está última entidad, el aseguramiento del $100 \%$, a través de su aseguradora Fiduprevisora S.A.

\section{ESTUDIO JURISPRUDENCIAL SOBRE LA RESPONSABILIDAD CONTENCIOSO ADMINISTRATIVA EN SALUD PENITENCIARIA}

La responsabilidad del Estado es el parámetro fundamental de intervención en el ejercicio de su acción u omisión, en el contexto de la protección y reconocimiento de los derechos fundamentales de las personas privadas de la libertad, especialmente en el campo del derecho humano a la salud. Es por ello que hay que tener en cuenta que la cláusula general de la responsabilidad del Estado se encuentra consignada en el artículo 90 de la Constitución Política de Colombia, el cual consiste en la configuración del daño antijurídico, producto de una lesión de un interés legítimo, patrimonial o extrapatrimonial, en el que la víctima no está en la obligación jurídica de soportar, sea por la acción o por la omisión de las autoridades públicas.

Para Rodríguez (2005) "la responsabilidad antijurídica para que sea existente se necesita de dos condiciones: 1 ) Que exista un daño de esa naturaleza; y 2) Que dicho daño sea imputable a una persona de derecho público" (p. 505).

Estas dos condiciones permiten inferir que la característica fundamental para el establecimiento de la responsabilidad del Estado no solo implica el fundamento constitucional, sino que también la armonización con los principios de solidaridad, protección por parte de las 
autoridades de la república sobre la vida, honra y bienes, el derecho a la igualdad y de la garantía del derecho a la salud (artículos 1, 2, 13 y 49 de la CN), otorgando principalmente que el centro de interés en el ámbito constitucional colombiano es el respeto de la dignidad humana, como facultad intrínseca y extrínseca que tiene la persona dentro del Estado Social de Derecho.

Indudablemente, el rol del Estado es ser garante y salvaguarda de los derechos y libertades de los particulares frente a la actividad de la administración, y que según Tascón (1933), resalta principalmente que si hay admisión de responsabilidad en el marco jurídico de la Constitución de un país, se debe acatar bajo el régimen de garantías jurídicas o de exigencias que se estiman esenciales para la realización de una vida digna del hombre y del ser humano, y como fórmula viva del Estado sometido al derecho.

Dentro del escenario penitenciario y carcelario, las obligaciones del Estado colombiano con la población privada de la libertad se encuentra enmarcada en una relación especial de sujeción, que consiste en el deber de protección y cuidado de este sector poblacional específico, estableciendo principalmente un régimen jurídico (Ley 65 de 1993-Código Nacional Penitenciario y Carcelario), por medio del cual se adopta las fases de especial tratamiento de la libertad y de los derechos fundamentales, así como también, producto del intervencionismo de las autoridades carcelarias de brindar la guarda, seguimiento, custodia y garantía de los derechos a la vida, integridad física y la salud.

Sobre esto último, se debe considerar que hacen parte de una relación directa con la dignidad humana, y que son considerados "derechos intocables"; la acción u omisión a esos derechos ha dado lugar a establecer dos escenarios de régimen de responsabilidad por daño antijurídico y su título de imputación, como se expresa a continuación.

a) Daño especial: se presenta por el rompimiento al equilibrio de las cargas públicas, generando una conducta que transforma la realidad de la administración, es decir, la población privada de la libertad al estar concentrada bajo vigilancia, custodia y protección a cargo de la autoridad carcelaria, y al ostentar la condición de encarcelamiento, no están en la capacidad de resistir agresiones, ataques, tratos crueles inhumanos y degradantes, respecto a agentes estatales (guardianes y dragoneantes), y terceros, dado que este tipo de acciones encaminan contra la PPL, por el hecho de estar en estado de detención, no son una carga que deban soportar.

b) Falla en el servicio: consiste en una característica del hecho generador, que nace como producto de la relación entre el daño y el nexo causal, dando surgimiento a que el Estado se equivoca en la prestación del servicio, de forma omisiva, retardada y defectuosa, es decir, en el escenario penitenciario y carcelario, conlleva a que las autoridades incurren en acciones $\mathrm{u}$ omisiones constitutivas de falta o falla en el servicio, por efecto de una causa ilícita o lícita; generándose como producto el incumplimiento del deber de asumir la posición de garante.

De acuerdo con esta último, se debe entender que el Estado se convierte en guardador y protector del ciudadano, en concreto, frente a la población privada de la libertad en materia de accesibilidad, cobertura y prestación del servicio de salud, el régimen de responsabilidad por daño antijurídico aplicable en lo relacionado con el título jurídico de imputación es sin duda la falla en el servicio, por cuanto cumple características principales de i) ser de carácter objetivo, ii) que proviene de una causa ilícita o licita, iii) su existencia se configura en un título jurídico de imputación, y iv) la observancia de la antijuridicidad del daño.

Con referencia a lo anterior, el componente principal del estudio jurisprudencial sobre la protección y el reconocimiento del derecho a la salud en materia carcelaria, desde la visión contencioso administrativo, ha conllevado 
al Consejo de Estado a sentar las siguientes precisiones jurídicas respecto del tema y sus respectivos alcances:

- Consejo de Estado. Sala de lo Contencioso Administrativo, Sección Tercera, Subsección A. Sentencia de 19 de noviembre de 2015. Rad. 19001-23-31-000-2001-00218-01 C.P. Martha Nubia Velásquez Rico. Tema: Relación Especial de Sujeción

En esta oportunidad, el alto tribunal de lo Contencioso Administrativo ha considerado que el régimen de responsabilidad aplicable a los daños causados a los reclusos es el objetivo a la atención a las relaciones especiales de sujeción entre estas personas y el Estado, pues en virtud de la restricción de derechos que conlleva la pena privativa de la libertad, quedan subordinados a su poder. No obstante, de acuerdo con los principios inspiradores del Estado Social de Derecho, los derechos a la vida, la integridad personal y la dignidad humana en ningún caso pueden ser suspendidos so pena de que surja una responsabilidad estatal.

Así pues, se comprende que la privación de la libertad de una persona implica necesariamente la subordinación de la PPL frente al Estado, generándose una relación jurídica especial de sujeción, en donde el rol del Estado a través de las instituciones tiene la facultad legal y constitucional de restringir, limitar o modular algunos derechos fundamentales, con el propósito principal de resocializar a la PPL, sin trasgredir los derechos a la vida, integridad personal y salud, que no son objeto de suspensión y limitación, sino que deben ser garantizados y respetados por las autoridades penitenciarias y carcelarias, a efectos de evitar la materialización de la vulneración, omisión y retardo en el radio de acción y ejercicio de sus competencias.

- Consejo de Estado. Sala de lo Contencioso Administrativo, Sección Tercera, Subsección A. Sentencia de 17 de abril de 2013. Rad. 25000-23-26000-2002-0́01470-01 C.P. Mauricio Fajardo Gómez. Tema: Procedibilidad

\section{de la Responsabilidad Patrimonial por Deficiente Prestación del Servicio de Salud}

Sobre el particular, el Consejo de Estado manifestó que los perjuicios derivados por una deficiente prestación del servicio de salud se pueden imputar a los centros penitenciarios y carcelarios, a partir de tres supuestos distintos que son:

i) Los daños derivados de una deficiente prestación de la actividad médico asistencial propiamente dicha que se le haya prodigado a la víctima directa por el personal vinculado al centro carcelario, es decir, por el servicio de sanidad del establecimiento de reclusión;

ii) la dilación en la remisión del recluso/ paciente a un centro especializado para su diagnóstico y tratamiento en la medida en que dicha demora haya contribuido a la causación del daño; y

iii) la ausencia de vigilancia y control de los centros médico- asistenciales con los cuales exista un convenio de atención de los reclusos, o la omisión en contar con dichos convenios para el tratamiento de los internos, en la medida en que el perjuicio haya sido producto de la ausencia de medios físicos y humanos para la prestación adecuada del servicio de salud o, aun cuando existan estos no sean aptos para su debida realización. (p. 35)

Ante la situación planteada y expuesta por el Consejo de Estado, la conducencia de imputación por falla en el servicio y la declaratoria de responsabilidad administrativa frente a los establecimientos penitenciarios y carcelarios en lo relacionado con la salud de la PPL, parte inicialmente del hecho que de forma permanente, el INPEC debe acudir a garantizar sea dentro o fuera del plantel penitenciario, la logística de traslado de atención especializada y los instrumentos médico-asistenciales que requiera la PPL, que incluso debe ser conexa a brindar calidad, oportunidad y eficiencia, por medio de los cuales se logre 
la accesibilidad y la protección de esta población, especialmente en la atención a cada situación que se presenta en particular.

- Consejo de Estado. Sala de lo Contencioso Administrativo, Sección Tercera, Sentencia de 10 de agosto de 2001. Rad. 50001-23-31-000-19944506-01 C.P. Alier Eduardo Hernández Enríquez. Tema: Responsabilidad Estatal por falla en el servicio por daños sufridos por los reclusos $y$ normatividad en la materia

Se indica en esta oportunidad que el Consejo de Estado concluyó que las controversias relacionadas sobre la responsabilidad extracontractual del Estado, originadas en daños sufridos por los reclusos, derivados de la prestación del servicio de salud por parte del establecimiento penitenciario, se deben resolver acudiendo a la noción de falla del servicio, sin perjuicio de que se pueda dar aplicación al principio de las cargas probatorias dinámicas, y con él, a las presunciones de falla, cuando el caso concreto lo amerite y en el entendido de que el cumplimiento de dicho compromiso, como la precisado la Sala, excluye los deterioros normales y explicables de ella (la salud), a la luz de la ciencia médica, o mejor aún, las enfermedades y problemas de salud inherentes ordinariamente a la misma naturaleza del ser humano, pues estas circunstancias configuran una causal eximente de responsabilidad estatal que es el hecho de la víctima.

Además, en materia de prestación del servicio de salud en los centros de reclusión, es preciso remitirse a los artículos 104 al 106 de la Ley 65 de 1993, esto es el Régimen Penitenciario y Carcelario.

En el Reglamento General del INPEC, Resolución 7965 del 27 de octubre de 1995 , arts. 46 a 49 , se establece que a cada establecimiento carcelario corresponde organizar lo concerniente a la prestación de los servicios de salud, tanto curativa como preventiva, a la que se refiere el artículo 106 de la Ley 65 de 1993, y se debe asignar la responsabilidad de su coordinación a un médico de planta.

Así mismo, se atribuye al grupo de enfermería, o a quien el director del centro de reclusión designe, el control sobre el consumo y posología de los medicamentos prescritos a los internos por el médico. Se prevé que si el centro de reclusión no está en capacidad de brindar atención médica de urgencias, el director del establecimiento, previo concepto del médico, ordenará trasladar inmediatamente al recluso a un centro hospitalario que aquél designe o al que indique el interno o sus familiares, caso en el cual serán ellos quienes sufraguen los gastos que por dicha atención se causen.

Dispone también el Régimen Penitenciario y Carcelario que se habrá de efectuar examen médico al detenido cuando ingrese al centro de reclusión, así como al momento previo a su excarcelación (art. 71). Igual previsión se halla contenida en el Reglamento General del INPEC (art. 15, inc. 4). Como lo señala el artículo 67 del referido Régimen, la dotación de elementos y equipos de sanidad estará a cargo del Instituto Nacional Penitenciario y Carcelario.

En este sentido, el Decreto 1242 del 30 de junio de 1993, asignó a dicha institución la función de adquirir y suministrar a los centros de reclusión los productos y elementos farmacéuticos, médicos y odontológicos que se requieran (art. 6ํㅡ, núm. 11); de igual forma, determinó como funciones de su División de Sanidad las de planeación, coordinación y supervisión de la atención médica preventiva y curativa para los reclusos.

De las anteriores consideraciones se deduce que los daños sufridos por la PPL, en materia de salud, se identifica principalmente en un asunto de prioridad estatal, en la que se debe enmarcar como agenda de política pública, en el sentido de que la atención y acceso a los servicios de salud ha sido impedido por las crecientes constantes de carencia en la infraestructura carcelaria, el aumento creciente del hacinamiento 
de los establecimientos penitenciarios, la intervención mínima de personal de salud en las áreas de sanidad y la logística, traslado y remisión a centros médicos especializados han sido causas en las que la actividad administrativa del INPEC, ha sido omisiva, retardada y defectuosa, ocasionando la materialización de la responsabilidad del Estado, que incluso, a pesar del gran compendio normativo en los escenarios nacional e internacional relacionado a las PPL, que genera la creación de áreas de sanidad y enfermería, es sin lugar a dudas que la falta de presupuesto, financiamiento y de sostenibilidad repercuta en la crisis institucional y de emergencia carcelaria, que actualmente se vive, dejando de lado la universalidad y goce efectivo de los derechos humanos, que tiene este sujeto colectivo poblacional.

- Consejo de Estado. Sala de lo Contencioso Administrativo, Sección Tercera, Subsección C. Sentencia de 12 de junio de 2014. Rad. 2500023-26-000-2000-01780-01. C.P. Olga Mélida Valle de la Hoz. Tema: Responsabilidad patrimonial en la contratación de prestación de servicios en atención médica a internos

En esta oportunidad, el Consejo de Estado señaló que frente a los servicios hospitalarios especializados a varias personas privadas de la libertad en una empresa social del Estado, no solamente se debe acreditar la prestación del servicio médico, sino que además la autorización o solicitud de la entidad (orden de remisión), por medio de las que revista unas actuaciones de carácter urgente y necesario, para evitar una amenaza o una lesión inminente e irreversible al derecho a la salud, de varias personas privadas de la libertad, los cuales debido al padecimiento que sufrían, fueron ingresados por urgencia al centro hospitalario.

Sobre este caso en particular, reside el estudio adecuado de la responsabilidad patrimonial, por cuanto surge la obligación del Estado de pagar los servicios médicos y hospitalarios, demostrando la existencia de un contrato estatal de prestación de servicios. Sin embargo, pese a la informalidad del contrato de prestación de servicios médicos celebrado con el INPEC, bajo los principios de justicia material y de iura novit curia ${ }^{5}$, la controversia resultante producto de la no cancelación de las facturas por servicios médicos, se debió llevar a cabo bajo la figura jurídica de la actio in rem verso ${ }^{6}$. Aunque se acreditó la responsabilidad a partir del hecho del retardo y el incumplimiento de pago por parte del INPEC, hacia la E.S.E, bajo la teoría de enriquecimiento sin causa a un justo medio, en tres aspectos: i) cuando su conducta provoca el desplazamiento económico injustificado de un patrimonio a otro, ii) la existencia de la liberalidad pura; y iii) la consecución de actos de engaño o dolo del particular. Por ende, la actuación del INPEC al no cancelar las facturas de prestación de servicios médicos hacia la E.S.E. ha generado no solamente el retardo, sino también la responsabilidad patrimonial de asumir el perjuicio acaecido; adicionando también, la orden de la compensación económica.

De las consideraciones expuestas en la presente sentencia, se puede inferir que efectivamente la accesibilidad, el reconocimiento y la prestación de los servicios médicos en favor de la PPL, en lo relacionado con la especialidad médica en centros hospitalarios y empresas sociales del Estado, implica principalmente en aunar esfuerzos presupuestales, de logística y contractuales, por medio de los cuales se garantice el derecho a la salud, de carácter fundamental y en conexidad con los derechos a la vida e integridad personal, en especial cuando las decisiones de la administración penitenciaria y carcelaria asuman obligaciones de hacer y de dar, toda vez que debe ser reconocido pecuniariamente el costo económico de los servicios médicos, es decir, la atención a urgencias, puesto que en el escenario y el rol de los hospitales y empresas sociales del Estado, la retribución por el pago de los servicios prestados, conlleva a la salud a ser

\footnotetext{
5. El juez conoce el derecho

6. Acción de enriquecimiento sin causa.
} 
un derecho económico y social que indica el deber de cobertura, acceso y permanencia que debe garantizar el Estado; todo ello en el marco constitucional del Estado Social de Derecho.

- Consejo de Estado. Sala de lo Contencioso Administrativo, Sección Tercera, Subsección A. Sentencia de 30 de agosto de 2018. Rad. 4100123-31-000-2001-00573-01. C.P. María Adriana Marín. Tema: Daño a la salud

En relación con este escenario, el Consejo de Estado estableció que en materia de responsabilidad objetiva, se identifica el daño a la salud como una tipología de perjuicio autónomo que garantiza la reparación estática y dinámica, con efectos internos y externos, subjetivos y objetivos, individuales y colectivos; en este la lesión antijurídica desencadena en el sujeto y las personas constituyen su entorno.

El concepto de salud comprende diversas esferas de la persona, razón por la que no solo está circunscrito a la interna, sino que comprende aspectos físicos y psíquicos, por lo que su evaluación será mucho más sencilla, puesto que ante lesiones iguales corresponderá una indemnización idéntica.

Por lo tanto, no es posible desagregar o subdividir el daño a la salud o perjuicio fisiológico en diversas expresiones corporales o relacionales (v.gr. daño estético, daño sexual, daño relacional familiar, daño relacional social), pues este tipo o clase de perjuicio es posible tasarlo o evaluarlo, de forma más o menos objetiva, con base en el porcentaje de invalidez decretado por el médico legista.

Esta modalidad de resarcimiento se repara con base en dos componentes: “i) componente objetivo, determinado con base en el porcentaje de invalidez decretado; y ii) componente subjetivo, que permitirá incrementar en una determinada proporción el primer valor, de conformidad con las consecuencias particulares y específicas de cada persona lesionada" (Fernández, 2014, párr. 42). Además, el daño a la salud tiene como base de resarcimiento los principios de igualdad y objetividad, a fin de satisfacer la máxima expresión de "a igual daño, igual indemnización".

En el escenario penitenciario y carcelario se presentó este tipo de daño a un hombre privado de la libertad, que fue herido con arma corto punzante, afectando la vena aorta, el colon y el duodeno, situación que dio lugar a que el INPEC, lo remitiera a un hospital de Neiva, a fin de ser intervenido quirúrgicamente y hospitalizado por 16 días, resultando para el interno una afectación a su salud. A pesar de la situación expuesta, no fue posible acreditar la incapacidad en cuanto al tiempo, y mucho menos en los elementos de prueba, se hubiere demostrado que producto de la lesión ocasionada, se estableciera el porcentaje de su capacidad laboral.

Lo anterior da lugar a que el daño a la salud es una clase de daño personalísimo que repercute en la configuración de tres aspectos, así:

i) la gravedad de la lesión (reparación dinámica), que constituye la valoración del juez contencioso administrativo mediante un ejercicio de arbitrum iudicis; ii) el porcentaje de invalidez (reparación estática) que dictamina el médico legista a través de peritaje, como también complementario a ello, el acervo probatorio testimonial y documental, que permite la conducencia y la identidad en la ocurrencia de los hechos; y iii) la edad de la víctima que se acredita principalmente con la prueba documental directa del registro civil de nacimiento.

En este sentido, el Estado en cabeza del INPEC asume su obligación de protección y seguridad, en virtud de hacerse responsable de los perjuicios que sufren las personas privadas de la libertad, tanto en sus obligaciones de hacer y no hacer. Frente a la primera, se debe entender la prevención y 
control de los peligros que pueda sufrir una persona retenida desde el momento mismo en que se produce la privación material de la libertad, hasta el momento mismo en que ella es devuelta a la sociedad; mientras que la segunda se refiere a la abstención de cualquier conducta que pueda vulnerar o poner en situación de peligro, los derechos que no hayan sido limitados con la medida cautelar.

\section{El goce efectivo de los derechos humanos mínimos constitucionalmente asegurables en el establecimiento penitenciario de mediana seguridad y carcelario de Tunja}

Frente a este ítem, la Defensoría del Pueblo-Regional Boyacá, como autoridad de control humanitario, ejerció una vigilancia al EPMSC de Tunja, relacionado con la materialización y goce efectivo de los DDHH, como derechos mínimos constitucionalmente asegurables de la PPL, entre ellas se destaca los siguientes hallazgos en materia de protección y reconocimiento frente al particular, así:

\section{- Materia de administración de justicia}

En primer lugar, El EPMSC de Tunja cuenta con un canal de comunicación entre los PPL del centro de reclusión y la administración carcelaria para facilitar el recibo de peticiones, en el que ello se destaca participación de un cónsul de DDHH, que es el responsable de la atención al ciudadano y el director del establecimiento penitenciario se entrevista de manera permanente con la población privada de la libertad.

Vinculado a lo anterior, también existe comunicación entre la población privada de la libertad en situación de discapacidad (limitaciones visuales y motrices) del centro de reclusión y la administración carcelaria para facilitar el recibo de peticiones, y que a la fecha, se reportan en la actualidad tres personas con discapacidad, sin entorpecer ni obstaculizar la recepción y respuesta a interposición de peticiones.

En segundo lugar, el establecimiento penitenciario cuenta con un reglamento interno en el procedimiento para garantizar el acceso a la administración de justicia de la población privada de la libertad, mediante la Resolución 6349 de 2015; así como también se ejerce dentro de los términos de ley, las respuestas a los derechos de petición interpuestos por la población PPL, y se realiza un apoyo de gestión a dicha respuesta entre uno de los representantes del Comité de Derechos Humanos (una PPL), y la oficina jurídica del establecimiento.

En tercer lugar, existe la comunicación por parte del establecimiento a la población PPL, para que realicen peticiones respetuosas a través de la oficina de atención al ciudadano y en brigadas jurídicas, convocados por el EPMSC de Tunja. En cuarto y último lugar, los jueces de ejecución de penas y medidas de seguridad del municipio de Tunja no frecuentan en asistir al EPMSC de Tunja, debido a la carga laboral que se presenta en cada uno de sus despachos, debido a que esta corporación judicial asiste una vez al año.

\section{- Alimentación}

En este ámbito, en la prestación del servicio de alimentación en el EPMSC de Tunja se garantiza la inocuidad de los alimentos entregados a la PPL, a partir del procedimiento de:
i) Transporte;
ii) Almacenamiento;
iii) Preparación de alimentos;
iv) Horario ajustado al común de la sociedad; $y$
v) La entrega de alimentos es de forma oportuna.

Adicionalmente, el personal médico del establecimiento realiza inspecciones regulares y asesora al director respecto a la cantidad, calidad, preparación y distribución de los alimentos, con la finalidad de asegurar el valor nutritivo de los mismos sea suficiente para el mantenimiento de la salud de la 
PPL; como también se vigila por parte de la nutricionista contratada por la empresa de alimentos - Pro Alimentos Líber S.A.S, acerca de la calidad de los alimentos entregados a la PPL, bajo el propósito de dar cumplimiento con los requisitos mínimos exigidos a estándares de salud pública para alimentos.

En cuanto a las instalaciones y estructura física de las áreas de preparación se encuentran en buen estado y sin fisuras; lo que permite realizar adecuadamente el aseo y desinfección del rancho. Esto lo realizó el EPMSC de Tunja. El mantenimiento reciente al rancho con cambio de baldosas y enchapes, permite que dicha zona sea utilizada para suministrar servicios alimentarios salubres, y de utilización de elementos de menaje óptimos (ollas, fondos y cambio de fiambrera a las PPL). Empero, respecto a espacios y mesas que utilizan para el consumo de alimentos para la PPL, a la fecha en el EPMSC de Tunja no se cuenta con comedores.

Se destaca también que el servicio de alimentación es suministrado a las PPL, cuando estos son trasladados a otros sitios, a partir de remisiones, se entrega el refrigerio a los sujetos poblacionales, así:

i) Despachos judiciales,

ii) Hospitales,

iii) Clínicas, y

iv) Centros médicos.

Por último, con relación las áreas del rancho del EPMSC de Tunja cuentan con:

i) Adecuada iluminación para todas las secciones según lo requieran los procedimientos 0 características técnicas,

ii) Dotación de llaves de agua potable y desagües que permiten la limpieza fácil de los materiales en procedimiento de lavado y descontaminación,

iii) Áreas independientes para el almacenamiento de alimentos, como cavas de congelación, refrigeración y medio ambiente que se encuentran actualmente en buen estado, y

iv) Sistema de ventilación en buen estado, adecuada e idónea para prevenir la contaminación cruzada de alimentos.

\section{- Obligaciones de los entes territoriales}

En materia de obligaciones de los entes territoriales, el EPMSC de Tunja, a la fecha no cuenta con un convenio interinstitucional relacionado con la regulación de la población sindicada con el municipio de Tunja, ni con el departamento de Boyacá, como tampoco se evidencia suscripción de convenios anteriores que se encuentren en ejecución.

Por ende, si hay un compromiso institucional, de cooperación y de solidaridad relacionado a la declaratoria de Estado de Cosas Inconstitucional desde 2013, por parte de las entidades territoriales en favor del funcionamiento del EPMSC de Tunja, a saber:

i) Un vehículo automotor, para el traslado de PPL, a diligencias de tipo médicas, asistenciales y judiciales;

ii) Un sistema de circuito cerrado de televisión al interior del establecimiento;

iii) Kits de aseo;

iv) Elementos de cama (colchonetas y cobijas), $\mathrm{y}$

v) Combustible.

\section{- Resocialización en el EPMSC deTunja}

Uno de los elementos fundantes de finalidad de la pena es iniciar la resocialización como un derecho que inculca en las PPL, la voluntad de vivir conforme a la ley, con la capacidad de suministrar su sustento diario, en cumplimiento de sus responsabilidades, dentro del marco constitucional y legal para poder vivir, para readaptarse nuevamente a la sociedad y comunidad, respetando siempre el principio de la dignidad humana, con lo que las actividades de orden laboral, educativo, deportivo y lúdico que se llevan a cabo en el EPMSC de Tunja, han otorgado el compromiso, oportunidad y disposición permanente de situarse el ser humano privado de la libertad, en una persona activa en cada una de las ocupaciones que ofrece el centro penitenciario:

i) Un plan ocupacional para el campo laboral, educativo, y deportivo. 
ii) Realización de campeonatos y actividades deportivas.

iii) Actividades lúdicas y musicales

Existe una red de apoyo y familiar para el seguimiento permanente durante el periodo de privación de la libertad, a través del apoyo de la iglesia, la familia cristiana y los fines de semana, el acompañamiento de los familiares privados de la libertad.

En el escenario de las necesidades para la población privada de la libertad, se requiere garantizar un adecuado proceso de resocialización que el EPMSC de Tunja proyecte en el presupuesto que se le asigne, como: la construcción de aulas de clase, campo deportivo amplio, cancha de baloncesto, escenarios y espacios suficientes para evidenciar en un alto grado, la garantía del proceso de resocialización mediante el ejercicio y la práctica de actividades laborales y deportivas.

\section{- Acceso a servicios públicos en el EPMSC de Tunja}

Frente a esta temática, en el EPMSC de Tunja se evidenció que no hay interrupción y/o restricción de los servicios públicos en el establecimiento, sin embargo, es preciso señalar algunas causas y necesidades derivadas de la sobrepoblación carcelaria que producirían una vulneración a la accesibilidad de estos servicios, así:

a) El centro penitenciario y carcelario de Tunja cuenta con redes suficientes y equipamientos para prestar los servicios públicos esenciales, pero debido a la existencia de hacinamiento y sobrepoblación carcelaria, el costo económico y monetario de asumir, y cubrir la esencia de la prestación de estos servicios, tenderá a hacer más complicado, y con consecuencias a futuro en materia de convivencia, orden público y de salubridad pública.

b) No se evidencia en el centro penitenciario, un registro del mantenimiento de las instalaciones y equipamientos. c) No se realiza por parte de las autoridades municipales, el monitoreo periódico de la prestación de los servicios públicos domiciliarios en el establecimiento, sino que sobre este punto, lo realiza una empresa particular.

d) Se evidencia la necesidad por parte del EPMSC de Tunja, en materia de servicios públicos, de aumentar la capacidad del servicio de energía y agua potable, debido al aumento de la población carcelaria, corriéndose el riesgo de que exista racionamiento, apagón y carencia de estos servicios, perjudicando el normal funcionamiento del establecimiento penitenciario.

En concordancia con los literales señalados, el EPMSC de Tunja cuenta con algunos aportes y verificación de procesos frente a la prestación y acceso a los servicios públicos domiciliarios:

a) Creación y disposición de un régimen de limpieza, desinfección y mantenimiento periódico de los equipos e instalaciones para la prestación de los servicios públicos, especialmente cuando se encargan labores de lavado de tanques, por lo menos dos veces al año.

b) El EPMSC de Tunja cuenta con capacidad de almacenaje de agua para un día, y cuando se presenta novedad por la falta de agua potable, se apoya por la Empresa de Acueducto y Alcantarillado (VEOLIA), a través de uso de carrotanques de agua.

c) La periodicidad para la realización de lavado y desinfección de tanques de almacenamiento en el establecimiento penitenciario, se realiza dos veces al año.

d) Mediante empresa particular se certifica con resultados de laboratorio, la calidad del agua entregada.

Así pues, se concluye frente a este punto del acceso y prestación de los servicios públicos domiciliarios, la salud de la 
población carcelaria se encuentra en un nivel de riesgo alto, debido a que se presenta a mayor demanda de la prestación de los servicios públicos a este sector poblacional, mayor es la responsabilidad y el compromiso por parte del EPMSC de Tunja, de solventar, proteger y reconocer a la población que tiene custodiada, tanto sindicada como condenada, porque a toda PPL se debe respetar sus condiciones de existencia, vida y dignidad humana.

Se debe brindar el acompañamiento y solidaridad no solamente de las autoridades carcelarias del nivel nacional (INPECUSPEC), sino también la colaboración de las secretarías de salud y de las entidades territoriales, de brindar escenarios y espacios de solución al hacinamiento carcelario -que actualmente no solamente Tunja lo asume, sino a nivel nacional como ocurre frecuentemente-, implicando la celebración de contratos interinstitucionales para aunar esfuerzos administrativos, económicos, presupuestales y de viabilidad, con la participación de entidades del sector privado, universidades y organismos de control humanitario en DDHH, a fin de observar y establecer un orden público satisfactorio y reducir el índice de población privada de la libertad en el municipio.

\section{CONCLUSIONES}

La investigación permitió evidenciar la existencia de la relación especial de sujeción entre Estado y población privada de la libertad en el escenario penitenciario y carcelario ha tenido un impacto negativo en materia de goce efectivo de los DDHH, a pesar de establecer por parte de la Corte Constitucional, la declaratoria de Estado de Cosas Inconstitucional, en Sentencias de Tutela T-153 de 1998, T-388 de 2013 y T-762 de 2015, en donde a la fecha, las autoridades estatales no han resuelto la protección y reconocimiento de este sector poblacional.

Por ello, en 2005 se evidenció un escenario carcelario de negación, débil y tenue, por cuanto se presentaron dificultades mediatas en salud y alimentación: i) traslado de enfermos a los centros asistenciales, ii) la falta de renovación de los contratos con las IPS, iii) la falta de suministro de útiles de aseo personal al momento de ingresar al penal, iv) los alimentos en mal estado y con fecha de consumo vencida, v) la presencia de moscas en cocina, depósito de alimentos, patios y alojamientos, vi) recipiente de materiales inservibles, contaminación de medicamentos y material paramédico en el consultorio médico, vii) la ausencia de equipos de servicios de urgencias, viii) la deficiencia en el valor nutricional de los alimentos suministrados, ix) el consumo de los alimentos por parte de la PPL en las celdas, y x) la falta de suministro de colchonetas.

A su vez, para 2012, el EPMSC de Tunja alcanzó un nivel prestacional más satisfactorio y humano a la salud, abonando como aportes principales, fundamentales y de responsabilidad institucional en pro de las PPL, las siguientes:

i) Prestación médica y atención básica a la PPL, por parte del área de sanidad por parte de un médico de medio tiempo nombrado por el INPEC y un médico nombrado por Caprecom E.P.S.

ii) Agendamiento de citas con especialistas, iii) La coordinación de servicios de salud a internos del sistema contributivo, iv) La reclamación de reportes de red externa, v) La realización de exámenes de ingreso y egreso; vi) Las valoraciones y conceptos para traslado, vii) El trabajo mancomunado de atención integral de internos por parte del personal de salud de Caprecom E.P.S, viii) Las brigadas de promoción y prevención relacionadas a consulta médica general, psiquiatría y odontología programada, higiene oral, urgencias por red externa, remisiones de red externa pos y no pos, procedimientos del auxiliar de enfermería, fórmulas dispensadas, toma de imágenes diagnósticas por red externa, toma de laboratorios intramural para lectura por red externa, cirugías, tratamientos tbc-VIH- cáncer y brigadas de optometría y salud oral (tamizaje visual, entrega de lentes y monturas, valoración para solicitud y entrega 
de prótesis dentales), actividades de prevención en nutrición, planificación familiar, sustancias psicoactivas, VIH, enfermedades de salud pública, transmisión sexual, cáncer de próstata y enfermedades del endotelio.

Seguidamente, de 2014 a 2016 el establecimiento penitenciario, mediante su área de sanidad, reportó una disponibilidad plena de personal (médico general, odontóloga, auxiliar de enfermería y enfermera profesional), realizándose actividades entre empleados, guardias, dragoneantes y personal complementario del INPEC en:

i) Campañas de vacunación contra influenza y hepatitis $A$,

ii) Lucha contra TBC - educación a guardia, familiares e internos,

iii) Campaña contra la lepra,

iv) Toma masiva de basciloscopias seriadas,

v) Pruebas de VIH,

vi) Búsquedas activas de sintomáticos respiratorios y de piel por parte de personal de sanidad, internos y guardia, vii) Educación en temas de promoción en salud y prevención de la enfermedad, viii) La realización de fumigaciones de las instalaciones y lavado de tanques,

ix) Valoraciones de ingreso y egreso de los internos,

x) Traslado de los pacientes según orden médica con base al estado de salud de la PPL,

xi) Suministro de medicamentos para enfermedades agudas y crónicas,

xii) Valoración y medicación de los pacientes con patologías mentales (bajo supervisión), y

xiii) La distribución, calidad, cantidad y preparación de los alimentos ofrecidos por parte de Servialimentar S.A.

En contraposición a los hallazgos de reconocimiento a la salud carcelaria en el municipio de Tunja, para el mismo 2016, el alcance prestacional del derecho humano a la salud en el EPMSC de Tunja tendió a caer en la problemática económica, contractual y presupuestal de no contar con i) médico intramural, ii) stock de medicamentos para suplir las necesidades de la PPL, iii) insumos médicos y odontológicos requeridos, $\mathrm{y}$ iv) servicio de recolección de residuos hospitalarios, lo cual afectó seriamente los principios de continuidad y cobertura de la prestación a las PPL, y que incluso se denota que el derecho humano a la salud tiende a no ser absoluta, sino con limitantes que derivan de un desbalanceo en el equilibrio económico del sistema del modelo de atención en salud penitenciaria.

Ante este tipo de circunstancias que derivan la vulneración al derecho a la salud, la participación de la población privada de la libertad, y los organismos de control humanitario (defensoría, personería y secretaría de salud del departamento) deben manifestar cualquier tipo de anomalía, queja, solicitud o denuncia que se presente frente a este tipo de consecuencias; tomando en cuenta que la exigibilidad en la protección de los derechos humanos y fundamentales de la PPL (principio pro homine) define el radio de acción de acudir a los mecanismos constitucionales (tutela-petición-popular), y de lo contencioso administrativo (reparación directa-declaratoria de responsabilidad por falla en el servicio y daño a la salud), con el objetivo de proteger no solamente la salud, como derecho fundante y esencial que deriva de otros, sino también la accesibilidad y protección en alimentación, agua potable, saneamiento básico, salubridad pública y ambiente sano.

Por otra parte, se debe destacar indispensablemente que en entre 2017 y 2018 se concluyó que el EPMSC de Tunja, en temas de capacitación, contratación y adecuación de infraestructura, se garantizó una coordinación entre el INPEC y el USPEC en salud, sobre:

i) Jornadas de capacitación personalizada con la participación del consorcio PPL 2017, el contact center y la subdirección de atención en salud de las PPL;

ii) La contratación de ocho empresas con licencia ambiental para el encargo de recolección, transporte, tratamiento y disposición final de los residuos 
hospitalarios generados en la atención en salud de las PPL;

iii) La financiación e inversión de vigencias futuras por parte de la Unidad de Servicios Penitenciarios y Carcelarios (USPEC), desde 2016, relacionado con temas de costos de la alimentación, salud de los internos y mantenimiento y construcción de cárceles; sobre esto último, para el EPMSC de Tunja, a partir de la declaratoria de emergencia carcelaria - Resolución 002390 del 10 de mayo de 2016; y

iv) Frente al régimen de visitas íntimas, el $61.9 \%$ de los establecimientos cuenta con área de vísitas íntimas, en el que se destacan los EPMSC de Ramiriquí, el Bordo, Tunja y Pedregal, que adecuaron el área con intervención de la vigencia actual financiada por la Unidad de Servicios Penitenciarios y Carcelarios (USPEC).

La otra tensión que se advierte en materia de acceso a la prestación de los servicios de salud carcelaria es el creciente y fluctuante índice de caracterización de población privada de la libertad en el EPMSC de Tunja, dejando en evidencia en el siguiente cuadro descriptor, que a simple vista, los años 2005, 2012, 2016, 2017 y 2019 presentaron el siguiente fenómeno:

Tabla 7. Índice de caracterización de población privada de la libertad en el EPMSC de Tunja

\begin{tabular}{|l|c|}
\hline Capacidad del EPMSC de Tunja & 120 PPL \\
\hline $\begin{array}{l}\text { No de personas privadas de la libertad } \\
\text { para } 2005\end{array}$ & $111 \mathrm{PPL}$ \\
\hline $\begin{array}{l}N^{\circ} \text { de personas privadas de la libertad } \\
\text { para } 2012\end{array}$ & $180 \mathrm{PPL}$ \\
\hline $\begin{array}{l}\mathrm{N}^{\circ} \text { de personas privadas de la libertad } \\
\text { para } 2016\end{array}$ & $232 \mathrm{PPL}$ \\
\hline $\begin{array}{l}\mathrm{N}^{\circ} \text { de personas privadas de la libertad } \\
\text { para 2017 }\end{array}$ & 223 \\
\hline $\begin{array}{l}\text { No de personas privadas de la libertad } \\
\text { para 2019 }\end{array}$ & 206 \\
\hline
\end{tabular}

Fuente: Elaboración propia
De lo anterior se puede inferir que la PPL en el EPMSC de Tunja ha sido fluctuante en el tiempo, teniendo presente que $2016 \mathrm{y}$ 2017, se mostró un alto índice de población carcelaria que afecta principalmente el goce efectivo de los DDHH de habitabilidad, lo cual da lugar a que los determinantes sociales que han marcado el fenómeno de hacinamiento carcelario:

i) La falta de una verdadera reforma a la ley penal,

ii) Los conflictos sociales que son causados por la falta de oportunidades y de distribución de bienes, servicios y necesidades básicas,

iii) La masificación de delitos cometidos contra las personas y la sociedad, como son violencia sexual, tráfico y venta de estupefacientes, homicidio, tentativa de homicidio, hurto, receptación y secuestro, $y$

iv) Los ambientes insalubres.

Todo este tipo de determinantes sociales conllevan al riesgo de la afectación al suministro de servicios públicos esenciales dentro del penal, como son la energía y el agua potable que tenderá a hacer un escenario complejo y de afectación a la convivencia y el orden público, en caso de presentarse apagones y racionamientos, lo cual también tiende a generar altos incrementos y costos económicos del servicio.

Además, frente a la salud, alimentación, saneamiento básico, sanitario y ambiental, la Defensoría del Pueblo y la Secretaría de Salud Departamental han dictaminado lo siguiente:

a) Como en 2005 hasta hoy, se sostiene en la posición de que no existe un lugar dentro del EPMSC de Tunja, de i) una atención de urgencias relacionado a instrumentalización, aparatos médicos, balas de oxígeno ni equipos de reanimación, en las que se pueda atender la gravedad de la situación de salud a las PPL, únicamente remitirán la urgencia al centro médico-Empresa Social del Estado-Hospital San Rafael de Tunja; ii) el mantenimiento preventivo 
y correctivo de equipos e instrumentos para la atención médica general; y iii) la carencia de un comedor comunitario para la utilización y consumo de alimentos para la PPL.

b) Para el EPMSC de Tunja, en la última visita arrojo unas condiciones sanitarias favorables por encima del 75 $\%$, en donde se hacen visitas periódicas, especialmente dos veces al año.

Finalmente, el EPMSC de Tunja se ha situado en un escenario de acompañamiento institucional y de solidaridad social antes y después de la declaratoria de emergencia carcelaria y penitenciaria en salud, en los años 2012, 2017 y 2018, evidenciándose los siguientes aportes:

i) La cátedra, capacitación y charlas alusivas sobre protección y respeto de la vida y a los semejantes, por parte de la ESAP, el SENA y la Defensoría del Pueblo, dirigido a la población privada de la libertad y funcionarios del INPEC, y que en ellas en salud, se evidencia la materia de primeros auxilios.

ii) Acompañamiento de la Alcaldía Mayor de Tunja, a través de la Secretaría de la Mujer-Equidad de Género y Desarrollo Social, sobre el informe de gestión "Mi Oportunidad", en materia de realización de atención psicosocial de cinco personas privadas de la libertad con su núcleo familiar, como tambien la actualización de la base de datos de 76 PPL de la ciudad de Tunja, en la cárcel distrital - EPMSC de Tunja.

iii) El trabajo mancomunado entre Personería y el EMPSC de Tunja, sobre realización de jornadas de cedulación, salud para monturas, y cajas de dentadura, como también se halla participación y vinculación a jornadas que ofrece el establecimiento como son: el día de la virgen de las mercedes (cada 24 de septiembre de cada año), y el día de los niños, por parte de la Personería, esta última asume como rol, la recolección económica para realización de esa jornada.

iv) La Intervención del Concejo Municipal de Tunja, cada 24 de septiembre de cada año, en brindar como acto humanitario, la entrega de alimentos y kits de aseo a la PPL.

v) El compromiso institucional, de cooperación y de solidaridad, relacionado al Estado de Cosas Inconstitucional desde 2013, por parte de las entidades territoriales en favor del funcionamiento y movilización de los funcionarios y PPL del EPMSC de Tunja como son: a) un vehículo automotor, para el traslado de PPL, a diligencias de tipo médicas, asistenciales y judiciales; b) un sistema de circuito cerrado de televisión al interior del Establecimiento; c) kits de aseo; d) elementos de cama (colchonetas y cobijas); y e) combustible.

vi) El alcance de la colaboración cuando una PPL recobre su libertad, respetando el principio de Continuidad en el acceso a la prestación de servicios de salud mediante el Régimen Subsidiado, o si la persona percibe capacidad de pago, al régimen contributivo.

En contraposición de lo anterior, y a pesar de los esfuerzos institucionales en pro de la protección de los derechos humanos y fundamentales de las personas privadas de la libertad en el EPMSC de Tunja, considerado por parte de la Defensoría del Pueblo-Regional Boyacá, como uno de los establecimientos penitenciarios y carcelarios menos hacinados del país, en comparación con otros ERON, los alcances de apoyo y colaboración han sido insuficientes, debido a que la problemática carcelaria, relacionada a hacinamiento, malos servicios de salud, e infraestructura, se ha convertido para las entidades territoriales, en un acto de negligencia extrema, en donde el Gobierno Nacional tiene la obligación principal de destinar los recursos para la sostenibilidad del funcionamiento de los centros penitenciarios territoriales, superar de forma progresiva el Estado de Cosas Inconstitucional y garantizar el respeto, goce efectivo de los DDHH, la dignidad humana y la protección constitucional a la salud de la PPL, en criterios de universalidad, continuidad, cobertura, accesibilidad y afiliación a los servicios médicos y asistenciales dentro de los ERON, como también una vez se 
recobre la libertad por parte del interno, de garantizarle la inscripción al Sistema de Identificación y Selección de Potenciales
Beneficiarios de Programas Sociales SISBEN, si la PPL vive y reside dentro de la jurisdicción territorial tunjana.

\section{REFERENCIAS BIBLIOGRÁFICAS}

» Alcaldía Mayor de Tunja, Secretaría de la Mujer. (2017). Informe de Gestión de enero a junio de 2017 - Mi oportunidad. Tunja, Colombia: Alcaldía Mayor de Tunja. Obtenido de http://alcaldiatunja.micolombiadigital.gov.co/sites/alcaldiatunja/ content/files/000399/19915_201709agostoinfges1sem2017mioportunidad.pdf

» Camacho, E., \& García, G. (2013). Responsabilidad del Estado por daños ocasionados a los reclusos en los centros penitenciarios y carcelarios. Revista Iter Ad Veritatem. (11), I(11), pp. 179-196.

» Carmona, Z., \& Parra, D. (2015). Determinantes sociales de la salud: un análisis desde el contexto colombiano. Salud Uninorte. 31 (3), pp. 608-620.

» Consejo de Estado. (2001). Sala de lo Contencioso Administrativo. Sección Tercera. Sentencia de 10 de agosto de 2001-rad. 50001-23-31-000-1994-4506-01 C.P. Alier Eduardo Hernández Enríquez.

» Consejo de Estado. (2013). Sala de lo Contencioso Administrativo. Sección Tercera. Subsección A. Sentencia de 17 de abril de 2013, rad. 25000-23-26-000-2002ó01470-01 - C.P. Mauricio Fajardo Gómez.

» Consejo de Estado. (2014). Sala de lo Contencioso Administrativo. Sección Tercera. Subsección C, Sentencia de 12 de junio de 2014, rad. 25000-23-26-000-200001780-01 - C.P. Olga Mélida Valle de la Hoz.

» Consejo de Estado. (2018). Sala de lo Contencioso Administrativo. Sección Tercera. Subsección A, Sentencia de 30 de agosto de 2018, rad. 41001-23-31-0002001-00573-01 - C.P. María Adriana Marín.

» Consejo de Estado. (2015). Sala de lo Contencioso Administrativo. Sección Tercera. Subsección A. Sentencia de 19 de noviembre de 2015, rad. 19001-23-31-0002001-00218-01 - C.P. Martha Nubia Velásquez Rico.

» Consejo Superior de Política Criminal. (2018). Quinto Informe Semestral de seguimiento a la Sentencia T-762 de 2015. Bogotá, D.C.: Ministerio de Justicia y del Derecho. Recuperado de: http://www.politicacriminal.gov.co/Portals/0/documento/ Quinto_Informe_Semestral_de_Seguimiento_al_Estado_de_Cosas_Inconstitucional_del_Sistema_Penitenciario_y_Carcelario..pdf?ver=2018-12-21-150738-063

» Consejo Superior de Política Criminal-Ministerio de Justicia y del Derecho. (2018). Informe Semestral del Gobierno Nacional al Estado de Cosas Inconstitucional del Sistema Penitenciario y Carcelario. Bogotá: Consejo Superior de Política Criminal. Recuperdo de: https://drive.google.com/file/d/1p1l6I-zCSE74HRXh3nm1Vqdq3LLKogd/view

» Corte Constitucional de Colombia. (1998). Sentencia T-153 del 28 de abril 1998 . Sala Tercera de Revisión de la Corte Constitucional. M.P.: Eduardo Cifuentes Muñoz. Bogotá, D.C., Colombia.

» Corte Constitucional de Colombia. (2013). Sentencia T-388 del 28 de junio de 2013. Sala Plena de la Corte Constitucional de Colombia. M.P.: María Victoria Calle Correa. Bogotá, D.C., Colombia. 
» Corte Constitucional de Colombia. (2015). Sentencia T-762 del 16 de diciembre de 2015. Sala Quinta de Revisión. M.P.: Gloria Stella Ortiz Delgado. Bogotá, D.C., Colombia.

» De la Realidad. (2017). Inpec avanza en aplicar emergencia carcelaria. Recuperdo de: https://delarealidad.com/2017/03/12/inpec-avanza-en-aplicar-emergencia-carcelaria/

» Defensoría del Pueblo - Regional Boyacá. (2005). Informe de seguimiento a la situación penitenciaria y carcelaria. Defensoría del Pueblo - Regional Boyacá, Boyacá. Tunja, Colombia: Defensoría del Pueblo. Recuperado de: https://grupodeprisiones. uniandes.edu.co/images/stories/relatorias/PRISIONES-OCT2011/ENT. ESTATALES/DEFENSORIA/INFORMES/informedeseguimientoSF.pdf

» Defensoría del Pueblo. (2017). Análisis sobre el actual hacinamiento carcelario y penitenciario en Colombia. Bogotá, D.C.: Defensoría del Pueblo. Retrieved from Análisis sobre el actual hacinamiento carcelario y penitenciario en Colombia: http:// www.defensoria.gov.co/es/public/Informesdefensoriales/785/An\%C3\%A1lisissobre-el-actual-hacinamiento-carcelario-y-penitenciario-en-Colombia-Informesdefensoriales---C\%C3\%A1rceles-Informes-defensoriales---Derechos-Humanos. htm

» Diario Extra. (2016). Crece tasa de hacinamiento - Boyacá. Retrieved from Extra - El diario de todos: http://boyaca.extra.com.co/noticias/local/crece-tasa-dehacinamiento-boyaca-217483

» El Tiempo. (2004). En la cárcel de Tunja hay hacinamiento. Retrieved from Periódico el Tiempo: https://www.eltiempo.com/archivo/documento/MAM1501169

» Fiduagraria. (2016). Contrato de prestación de servicios de salud No. 59940. Bogotá, D.C., Colombia.

» Instituto Nacional Penitenciario y Carcelario. (2001). Resolución 0459 del 27 de diciembre de 2001. [Por la cual se crea el Establecimiento Penitenciario de Mediana Seguridad y Carcelario de Tunja]. Tunja, Colombia.

» Instituto Nacional Penitenciario y Carcelario. (2016). Circular 029 del 10 de mayo de 2016. [Contratación para la atención en salud de la población privada de la libertad a cargo del INPEC]. Bogotá, D.C., Colombia.

» Instituto Nacional Penitenciario y Carcelario. (2016). Resolución No. 002390 del 10 de mayo de 2016. D.G. Jorge Luis Ramírez Aragón. [Por medio de la cual se declara el Estado de Emergencia Penitenciaria y Carcelaria en los Establecimientos de Reclusión de Orden Nacional del INPEC]. Bogotá, D.C., Colombia.

»Instituto Nacional Penitenciario y Carcelario. (2016). Respuesta derecho de petición 149-EPMSCTUN interpuesto por el señor Nicolás Rodríguez Forero del 2 de mayo de 2016. Tunja, Boyacá, Colombia: MinJusticia.

» Instituto Nacional Penitenciario y Carcelario. (2017). Diagnósticos DDHH, Unidos por los Derechos Humanos, Grupo de Derechos Humanos, Dirección General INPEC. Unidos por los Derechos Humanos. Bogotá, D.C.: Instituto Nacional Penitenciario y Carcelario -INPEC- Diagnóstico Regional Central. Retrieved from http:// inpec.gov.co/web/guest/derechos-humanos/diagnosticos-ddhh/-/document_ library/1G3aCXSoP7MZ/view_ file/39358?_com_liferay_document_library_web_ portlet_DLPortlet_INSTANCE_1G3aCXSoP7MZ_redirect=http\%3A\%2F\%2Finpec. gov.co\%2Fweb\%2Fguest\%2Fderechos-humanos\% 
» Instituto Nacional Penitenciario y Carcelario. (2019). Oficio 8300-DIRAT del 9 de abril de 2019. Derecho de petición interpuesto por el sr. Nicolás Rodríguez Forero. Tunja, Boyacá.

» Juzgado Catorce Administrativo Oral del Circuito de Tunja. (2018). Sentencia de 21 de noviembre de 2018 Rad. 15001-33-33-014-2014-00124-00-Medio de Control: Reparación Directa, 15001-33-33-014-2014-00124-00 (Juzgado Catorce Administrativo Oral del Circuito de Tunja, noviembre 21, 2018).

» Ministerio de Salud y Protección Social. (2015). Resolución 00005159 del 1o de diciembre de 2015. Diario oficial No. 49.713. [Por la cual se adopta el Modelo de Atención en Salud para la población privada de la libertad bajo la custodia y vigilancia del INPEC]. Bogotá, D.C., Colombia.

» Ostos, N., \& Pardo, E. (2012). Informe de Rendición de Cuentas. Establecimiento Penitenciario de Mediana Seguridad y Carcelario de Tunja. Establecimiento Penitenciario de Mediana Seguridad y Carcelario de Tunja, Boyacá. Tunja, Colombia: INPEC.

» Personería Municipal de Tunja. (2016). Informe de Gestión - Personería de Tunja - Una ciudad con derechos. Tunja, Colombia: Personería Municipal de Tunja. Recuperado de http://personeriadetunja.gov.co/data/documents/INFORME-DE-GESTION-2016-PERSONERIA-TUNJA-1.pdf

» Procuraduría General de la Nación, Presidencia de la República y Defensoría del Pueblo. (2017). Tercer informe semestral de seguimiento a la sentencia T-762 de 2015. Bogotá, D.C.: Grupo líder de seguimiento - Procuraduría General de la Nación - Presidencia de la República y Defensoría del Pueblo. Retrieved from http://www. politicacriminal.gov.co/Portals/0/Informes\%20de\%20Seguimiento/Anexos\%20 3er\%20informe/Parte\%201_com.compressed.pdf?ver=2018-02-08-154928-853

» Procuraduría General de la Nación, Presidencia de la República y Defensoría del Pueblo. (2016). Primer Informe Semestral de Seguimiento a la Sentencia T-762 de 2015. Bogotá, D.C.: Procuraduría General de la Nación - Presidencia de la República y Defensoría del Pueblo. Retrieved from http://www.politicacriminal.gov. co/ Portals/0/Primer-Informe-Grupo-Lider-de-Seguimiento-Sentencia-T-762-de2015-ilovepdf-compressed-1-100.pdf?ver=2016-12-09-172038-980

» Procuraduría General de la Nación, Presidencia de la República y Defensoría del Pueblo. (2017). Segundo Informe Semestral de Seguimiento a la Sentencia T-762 de 2015. Bogotá, D.C:: Grupo líder de seguimiento, Procuraduría General de la Nación, Presidencia de la República y Defensoría del Pueblo. Retrieved from http:// www.inpec.gov.co/documents/20143/282221/Segundo+Informe+Corte+Constit ucional+9+junio+2017.pdf/58d703e3-1f15-19a3-430a-ffc6909eafb7

» Procuraduría General de la Nación, Presidencia de la República y Defensoría del Pueblo. (2017). Tercer informe semestral de seguimiento a la sentencia T-762 de 2015. Bogotá, D.C.: Grupo líder de seguimiento - Procuraduría General de la Nación - Presidencia de la República y Defensoría del Pueblo. Retrieved from http://www. politicacriminal.gov.co/Portals/0/Informes\%20de\%20Seguimiento/Anexos\%20 3er\%20informe/Parte\%201_com.compressed.pdf?ver=2018-02-08-154928-853

» Rodríguez, N. (2016). Derecho de petición interpuesto por el sr. Nicolás Rodríguez Forero del 15 de abril de 2016. Derecho de petición de información al Establecimiento Penitenciario y Carcelario de Tunja. Tunja, Colombia. 